Review Article

\title{
Key Markers and Epigenetic Modifications of Dental-Derived Mesenchymal Stromal Cells
}

\author{
Jingqiu Chen, Xiaodan Zheng, Nanquan Rao, Yao Huang, Juan Liu, Yanhong Li, \\ and Jun Zhang
}

Yunnan Provincial Key Laboratory of Stomatology, The Affiliated Stomatology Hospital of Kunming Medical University, Kunming, Yunnan, China

Correspondence should be addressed to Jun Zhang; zhangjun@kmmu.edu.cn

Received 29 January 2021; Revised 8 April 2021; Accepted 17 April 2021; Published 10 May 2021

Academic Editor: Ryan Moseley

Copyright (C) 2021 Jingqiu Chen et al. This is an open access article distributed under the Creative Commons Attribution License, which permits unrestricted use, distribution, and reproduction in any medium, provided the original work is properly cited.

\begin{abstract}
As a novel research hotspot in tissue regeneration, dental-derived mesenchymal stromal cells (MSCs) are famous for their accessibility, multipotent differentiation ability, and high proliferation. However, cellular heterogeneity is a major obstacle to the clinical application of dental-derived MSCs. Here, we reviewed the heterogeneity of dental-derived MSCs firstly and then discussed the key markers and epigenetic modifications related to the proliferation, differentiation, immunomodulation, and aging of dental-derived MSCs. These messages help to control the composition and function of dental-derived MSCs and thus accelerate the translation of cell therapy into clinical practice.
\end{abstract}

\section{Introduction}

Mesenchymal stromal cells (MSCs) are plastic-adherent fibroblast-like cells [1] that have self-renewal and multidifferentiation potential and strong proliferative ability [2-4]. Bone marrow mesenchymal stromal cells (BMMSCs) are widely recognized in tissue regeneration. However, there are several challenges to obtaining BMMSCs, including pain, morbidity, and low harvested cell number. Thus, alternative sources for BMMSCs must be identified [5, 6]. Dentalderived MSCs have unique clinical advantages, such as easy access and remarkable tissue reparative/regenerative potential, and they have been proposed as ideal candidates for MSCs-based tissue regeneration [7-9].

Tissue regeneration and maintenance are dependent on MSCs [10]. However, a barrier to realize the therapeutic potential of MSCs is their intrinsic heterogeneity, which is also observed for dental-derived MSCs [11-13]. Cell subpopulations within heterogeneous MSCs cultures vary in their regenerative potential, including proliferation potential [14], differentiation [15], and immunomodulatory ability [16]. In MSCs therapy, cells are the active substances in medicines. Although variation is inevitable, our limited ability to detect and control heterogeneity poses challenges for the production of MSCs therapies. Heterogeneity has been cited as a possible factor contributing to the variability in treatment outcomes of MSCs therapies in clinical trials [17-19]. Variation in the regenerative potential among cell subsets in MSCs cultures may confound trial results and slow or arrest the translation of MSCs therapy into clinical practice [20].

Cell-to-cell variation in MSCs function is initiated in vivo in the MSCs niche [21], is evident within single-cell-derived MSCs colonies, and is exacerbated by replicative stress during in vitro cultivation [22]. A focus of ongoing research on dental-derived MSCs heterogeneity is to elucidate key markers. Cellular key markers can be used to noninvasively and nondestructively isolate specific cell subpopulations from MSCs cultures for clinical applications and research [23]. It may also help to regulate the regenerative potential of dental-derived MSCs. Besides, recent studies suggest that epigenetic alterations in cells occur in response to intrinsic cellular inheritance and external environmental stimuli to maintain the homeostasis of cells and niche cells [24, 25]. Epigenetic modification stimulates potentially reversible changes to gene expression, thus presenting exciting opportunities for clinical dental-derived MSCs interventions. Here, 
TABLE 1: Characteristics of dental-derived MSCs.

\begin{tabular}{|c|c|c|c|c|}
\hline Cell type & Origin & Multipotentiality (in vitro) & Application & References \\
\hline \multirow{5}{*}{ DPSCs } & \multirow{5}{*}{ Dental pulp tissue } & Osteo/odontogenic & Immunoregulation & \multirow{5}{*}{ [213-217] } \\
\hline & & Adipogenic & Angiogenesis & \\
\hline & & Chondrogenic & Nerve iniure treatment & \\
\hline & & Vascular & Nerve injure treatminemt & \\
\hline & & Neurogenic & Dentin/pulp complex formation & \\
\hline \multirow{4}{*}{ SHEDs } & \multirow{4}{*}{$\begin{array}{l}\text { Human exfoliated } \\
\text { deciduous teeth }\end{array}$} & Osteo/odontogenic & Angiogenesis & \multirow{4}{*}[46,218-220]{} \\
\hline & & Adipogenic & & \\
\hline & & Chondrogenic & Dental/pulp complex formation & \\
\hline & & Neurogenic & & \\
\hline \multirow{3}{*}{ SCAPs } & \multirow{3}{*}{ Apical papilla } & Osteo/odontogenic & Dentin/pulp complex formation, & \multirow{3}{*}[221,222]{} \\
\hline & & Adipogenic & spinal injure treatment & \\
\hline & & Neurogenic & Angiogenesis & \\
\hline \multirow{4}{*}{ PDLSCs } & \multirow{4}{*}{ Periodontal ligament } & Osteo/cementogenic & Immunosuppressive effects & \multirow{4}{*}[8,223-225]{} \\
\hline & & Adipogenic & & \\
\hline & & Chondrogenic & Periodontal disease & \\
\hline & & Neurogenic & & \\
\hline \multirow{5}{*}{ DFCs } & \multirow{5}{*}{ Dental follicle } & Osteo/cementogenic & Periodontal tissue & \multirow{5}{*}[54,226,227]{} \\
\hline & & Odontogenic & Angiogenesis & \\
\hline & & Adipogenic & & \\
\hline & & Chondrogenic & Pulp tissue formation & \\
\hline & & Neurogenic & & \\
\hline \multirow{6}{*}{ TGSCs } & \multirow{6}{*}{$\begin{array}{l}\text { Apical papilla in the } \\
\text { developing tooth germ }\end{array}$} & Adipogenic & & \multirow{6}{*}[32,228,229]{} \\
\hline & & Osteogenic & & \\
\hline & & Neurogenic & Liver disease & \\
\hline & & Adipogenic & Dental defects & \\
\hline & & Chondrogenic & & \\
\hline & & Endothelial & & \\
\hline \multirow{4}{*}{ GMSCs } & \multirow{4}{*}{ Gingiva } & Osteogenic & & \multirow{4}{*}[31,43,230]{} \\
\hline & & Chondrogenic & Nerve regeneration, & \\
\hline & & Neurogenic & & \\
\hline & & Adipogenic & Immunomodulatory properties & \\
\hline
\end{tabular}

we first reviewed the heterogeneity of dental-derived MSCs. Then, we discussed the key markers and epigenetic modifications that support regeneration potential.

\section{Dental-Derived MSCs and Their Heterogeneity}

The oral region contains a variety of distinct MSCs populations, including mesenchymal stromal cells of dental pulp (DPSCs) [26], mesenchymal stromal cells of apical papilla (SCAPs) [27], mesenchymal stromal cells of human exfoliated deciduous teeth (SHEDs) [28], mesenchymal stromal cells of periodontal ligament (PDLSCs) [29], dental follicle cells (DFCs) [30], mesenchymal stromal cells of gingiva (GMSCs) [31], and mesenchymal stromal cells of human tooth germ (TGSCs) [32]. These dental-derived MSCs have less cytoplasm and are spindle-shaped, and they are positive for CD13, CD29, CD44, CD73, CD90, CD105, CD106, CD146, CD166, and CD271 but negative for CD3, CD8, CD11b (or CD14), CD15, CD19 (or CD79 $\alpha$ ), CD33, CD34, CD45, CD71, CD117, and HLA-DR [26, 27, 29, 33-35]. Since oral tissues develop from migrating cranial cells, dentalderived MSCs display ready availability and high proliferation ability [36, 37]. Moreover, they possess multidifferentiation potential and can differentiate into adipocytes [32, 38], chondrocytes [39, 40], osteoblasts [41, 42], neuronal cells [43-45], and endothelial cells [46, 47] (Table 1).

Issues related to cell heterogeneity are getting more and more attention in the field of MSCs research. A more comprehensive understanding of the variability of transplantable populations will help maximize the potential of any MSCs therapy [48]. According to the International Society for 
Cellular Therapy, dental-derived MSCs meet all the minimum criteria that define MSCs [49]. Even so, this definition does not necessarily identify a homogeneous population of MSCs. Instead, it describes a group of heterogeneous cells that exhibit variability at the level among tissues of origin, individual donors, clonal subpopulations, and single cells $[12,50,51]$.

\subsection{Tissue and Donor Heterogeneity and Functional} Variation. Every tissue or organ has its evolutionary origin. The composition of a tissue, in terms of cell types, stands behind the overall functionality. The heterogeneity of cell types increases throughout the evolution in every functional entity [52]. A large amount of evidence shows that MSCs from different tissues have differences in marker profiles, gene expression patterns, and tendency to differentiate into specific cell types [38, 53-55]. GMSCs were isolated and characterized as $90 \%$ derived from neural crest cells (cranial neural crest cell-derived GMSCs, N-GMSCs) and 10\% derived from the mesoderm (mesoderm GMSCs, MGMSCs). N-GMSCs express a high level of Fas-ligand (FasL), which induces $\mathrm{T}$ cell apoptosis and immune tolerance [56]. In comparison with M-GMSCs, N-GMSCs are more likely to differentiate into chondrocytes and neural cells in vitro and induce T-cell apoptosis [57]. Moreover, N-GMSCs can be induced into neural crest stem-like cells via the activation of RhoA-ROCK/Yes-associated protein 1 (YAP1) signaling [58]. These results indicate that N-GMSCs possess a superior capacity for immune regulation and differentiation than $\mathrm{M}$ GMSCs. Indeed, there is mounting evidence that cultured cells retain a "memory" of their previous environments [59-61]. The highly heterogeneous nature of DPSCs is believed to be due to multiple progenitor cell populations existing in different locations of the dental pulp that may have different proliferation and differentiation abilities [62]. Different niches have been found in situ associated with the vasculature, within the pulpal stroma, in the subodontoblast layer, and among peripheral nerve-associated glial cells [63].

In addition, even from the same tissue source, dentalderived MSCs show tremendous variability between donors $[13,64,65]$. Similarly, as donor age increases, MSCs availability, self-renewal capacity, and differentiation potential have been reported to decline. Many animal and human studies have established the effects of increasing donor chronological age on the impairment of dental-derived MSCs regenerative capabilities [66-69]. In studies that involved small numbers of clones obtained from multiple donors, differences in gene expression among clones obtained from multiple donors might have reflected the different genetic backgrounds of the donors, rather than phenotypic differences between multipotent MSCs and committed progenitor cells [70]. Analysis of gene expression profiles among clones obtained from a single donor may allow researchers to eliminate the differences in genetic backgrounds that are associated with the use of multiple donors [71].

\subsection{Clonal Heterogeneity and Functional Variation. Further} study revealed that the clonal variation of dental-derived MSCs superimposes the difference among tissue- and donordependent differences. For example, DPSCs from multiple colonies can reach more than 120 population doublings (PDs), while single-colony-derived DPSCs can proliferate only up to 10-20 PDs [13]. Approximately two-thirds of DPSCs derived from single colonies can form the same amount of dentin as multicolony DPSCs. The other one-third generated only a limited amount of dentin. Studies have demonstrated that each colony is originally derived from the clonal expansion of a single progenitor cell [72]. However, there is growing appreciation that cellular phenotype can be highly variable, even within a clone [22]. Within the same colony, DPSCs of different cell shapes and sizes may be observed. If seeded on dentin, some DPSCs will be transformed into odontoblastlike cells with polarized cell bodies and a cell process extending into the existing dentinal tubules [73, 74]. When SHEDs clones derived from a single colony are transplanted into immunodeficient mice, only a quarter of the clones have the same potential to generate ectopic dentin-like tissue equivalent to that produced by multicolony-derived SHEDs clones [28]. Thus, cell-to-cell variation exists at every level, where the heterogeneity between clones has been noticed, and this must be taken into account when using this cell type in any basic scientific research or clinical application [22].

Functional variation at multiple levels extends to the molecular and epigenetic status of MSCs [71, 75]. Young et al. reported the ability of murine DPSCs clones derived from single cells to differentiate into immature neuron-like cells and oligodendrocyte-like cells in vitro. Significantly, only DPSCs clones with high nestin mRNA expression levels successfully differentiated into microtubule-associated protein 2 (Map2) and neurofilament- (NF-) positive neuronlike cells [50]. Alraies et al. identified differences between high (A3) and low (A1 and A2) proliferative capacity DPSCs populations, even from the same pulpal tissue sample [76]. They found that high proliferative capacity DPSCs exhibited longer telomeres but lacked CD271. It suggested that proliferative and regenerative heterogeneity is related to contrasting telomere lengths and CD271 expression between DPSCs populations. A highly dynamic histone modification response was evident in mineralizing DFCs, but not in DPSCs, and the latter cell type expressed higher levels of the pluripotency-associated genes octamer-binding transcription factor- (OCT-) 4 and NANOG [77]. The authors concluded that the two neural crest-derived MSCs populations were distinguished by epigenetic repression of dentinogenic genes and the dynamic histone enrichment in DFCs during mineralization. It highlighted the essential role of epigenetic mechanisms in the terminal differentiation of dentalderived MSCs and lineage commitment.

Such functional variability may provide an opportunity to identify MSCs subpopulations that are most suitable to drive a series of tissue restoration [75]. Moreover, it motivates ongoing work to reveal molecular or epigenetic markers of MSCs differentiation potential, as discussed later in this review.

\section{Key Markers of Dental-Derived MSCs}

For the application of dental-derived MSCs in tissue engineering and regenerative medicine, it is important to 
optimize their isolation and preserve their phenotypic properties. The presence of key markers in the MSCs niche will help to break down the heterogeneous barrier of dentalderived MSCs $[20,78]$. This section summarizes the key molecules that regulate dental-derived MSCs proliferation, differentiation, immunomodulation, and aging in the MSCs niche. This study will provide key targets and a certain theoretical basis for maintaining MSCs characteristics and promoting MSCs-mediated tissue regeneration. Table 2 lists some key markers in the field of dental-derived MSCs.

3.1. Key Markers of Proliferation Potential. Dental-derived MSCs are a reliable cell resource for tissue regeneration, and they need to be expanded largely in vitro, which requires cells to have superior proliferation and self-renewal potential [79]. It is necessary to explore the key markers related to proliferation to provide useful information for obtaining highquality MSCs.

STRO-1 is a marker that recognizes a trypsin-insensitive epitope on perivascular cells, and it has been used to isolate MSCs populations from human and rat dental pulp and has shown enhanced proliferation potential [80]. Ranga Rao et al. found a gradual decrease in STRO-1 and transcription factor expression (OCT4, NANOG, and nestin) with an increase in the passage number of GMSCs [14]. A previous study showed that the STRO $-1^{+} / \mathrm{CD} 146^{+}$SCAPs demonstrated higher colony-forming unit (CFU) efficiency and much higher expression of several embryonic and neural markers (stage-specific embryonic antigen-3 (SSEA-3); Nanog; OCT3/4; and nestin) than nonsorted SCAPs and the STRO- $1^{-} / \mathrm{CD} 146^{+}$subpopulation [81]. Moreover, STRO $-1^{+}$selected DPSCs show effective hard tissue formation when seeded into a calcium phosphate ceramic scaffold $[82,83]$. These results suggested that STRO- $1^{+}$cells may represent a very promising adult MSCs source with enhanced multipotent MSCs properties.

Alkaline phosphatase (ALP) is abundantly expressed in undifferentiated cells, such as induced pluripotent stromal (iPS) cells/embryonic stromal (ES) cells, preimplantation embryos (2-cell embryos to blastocysts (inner cell mass)) and embryonic ectoderm at the egg-cylinder stage, primordial germ cells (PGCs), and immature spermatogenic cells [84]. ALP is also a marker of neuronal progenitor cells, human myogenic progenitor cells (also called "pericytes"), and BMMSCs [85-87]. Inada et al. found that among the five primarily isolated SHEDs, two exhibited higher degrees of ALP activity and higher OCT-3/4 expression. Furthermore, these two lines proliferated faster than the other three lines and were easier to program into iPS cells [88]. Moreover, $\mathrm{Yu}$ et al. found that the $\mathrm{ALP}^{+}$subpopulation of PDLSCs had higher levels of STRO-1 and CD146 than $\mathrm{ALP}^{-}$cells, even after a high number of passages. $\mathrm{ALP}^{+}$cells expressed significantly higher levels of stemness-associated genes, NANOG, OCT-4, and sex-determining region $\mathrm{Y}$ box- (SOX-) 2 than $\mathrm{ALP}^{-}$cells [89]. In summary, $\mathrm{ALP}^{+}$ cells may represent a population with a higher proliferation rate than $\mathrm{ALP}^{-}$cells. Further studies are needed to understand the roles of ALP in stemness in other dental subpopulations.
Nuclear factor I-C (NFIC) is regarded as a key regulator of tooth development. NFIC deficiency causes aberrant odontoblasts and abnormal dentin and periodontium formation, and it ultimately leads to short molar roots [90]. Zhang et al. found that overexpression of NFIC increases cell proliferation in SCAPs [91]. NFIC silencing could prolong the G1 phase of the cell cycle in SCAPs [92]. Moreover, Zhang et al. demonstrated that NFIC can markedly promote the proliferation of rat DFCs [93].

3.2. Key Markers of Differentiation Potential. The multipotent properties of dental-derived MSCs make them a valuable cell source for regeneration [6]. Osteogenic differentiation, chondrogenic differentiation, and adipogenic differentiation are the minimum requirements for the differentiation ability of MSCs. In addition, vascularity and innervation are two properties that cannot be sacrificed when considering tissue regeneration. In particular, a limitation of the apical foramen is that it requires the ingrowth of nerve fibers and blood vessels from apical tissues when regenerating parts of the tooth [94].

CD146 is a cell adhesion molecule and an integral membrane glycoprotein at the intercellular junction. It was originally identified as a tumor marker for melanoma [95]. Additionally, CD146 is a MSCs marker that is associated with angiogenic, neurogenic, and mineralization abilities [96]. $\mathrm{CD}_{146^{+}}$BMMSCs possess high migration ability and are stromal cells that support hematopoiesis [97]. Matsui et al. found that $\mathrm{CD} 146^{+}$DPSCs have higher mineralization ability than nonseparated cells, CD146 cells, and CD146 ${ }^{+/-}$cells. Moreover, transplanted CD $146^{+}$cells generated clear dentin/pulp-like structures in immunocompromised beige mice. Immunohistochemical studies detected dentin matrix protein-1 (DMP1), dentin sialophosphoprotein (DSPP), and human mitochondria in transplanted DPSCs [98]. This result suggests that $\mathrm{CD} 146^{+}$cells may exhibit a high osteoblastic potential, which is consistent with previous studies [99].

CD271 or p75 neurotrophin receptor (NTR) is a wellconserved transmembrane pro-neurotrophin/neurotrophin receptor that plays critical roles in the maintenance of nerve cell viability [100]. CD271 has been proposed to be a neural MSCs marker that defines a cell population with neurogenic potential in the adult brain subventricular zone (SVZ) [101] and subgranular zone (SGZ) [102]. CD271 is expressed at low levels $(<10 \%)$ in DPSCs. CD $271^{+}$DPSCs have higher expression levels of SOX1 (neural precursor cell marker), SOX2 (cell pluripotency marker), and nestin (neural stem cell marker) than CD271- DPSCs. This result suggests that CD271 ${ }^{+}$DPSCs may denote a subpopulation with greater neurogenic potential [103]. In addition, Alvarez et al. used a combination of the three surface markers CD51/CD140 $\alpha$, CD271, and STRO-1/CD146 to isolate homogenous populations of PDLSCs. CD271 ${ }^{+}$cells had a higher dental/osteogenic potential and led to the greatest upregulation of osteogenic marker genes, like distal-less homeobox 5 (DLX5), runt-related transcription factor 2 (RUNX2), and bone gamma-carboxyglutamate protein (BGLAP) during the induction process [15]. 


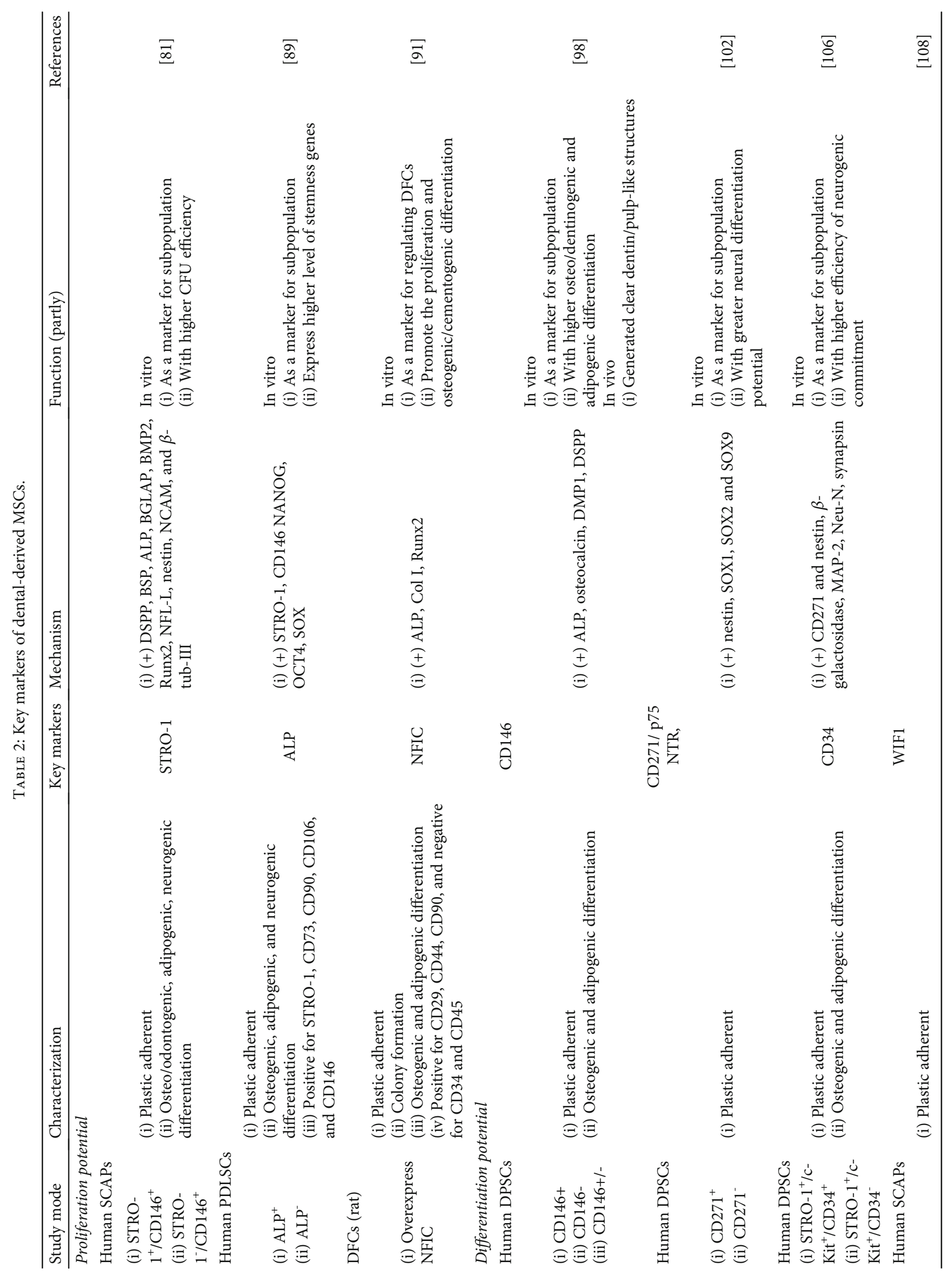




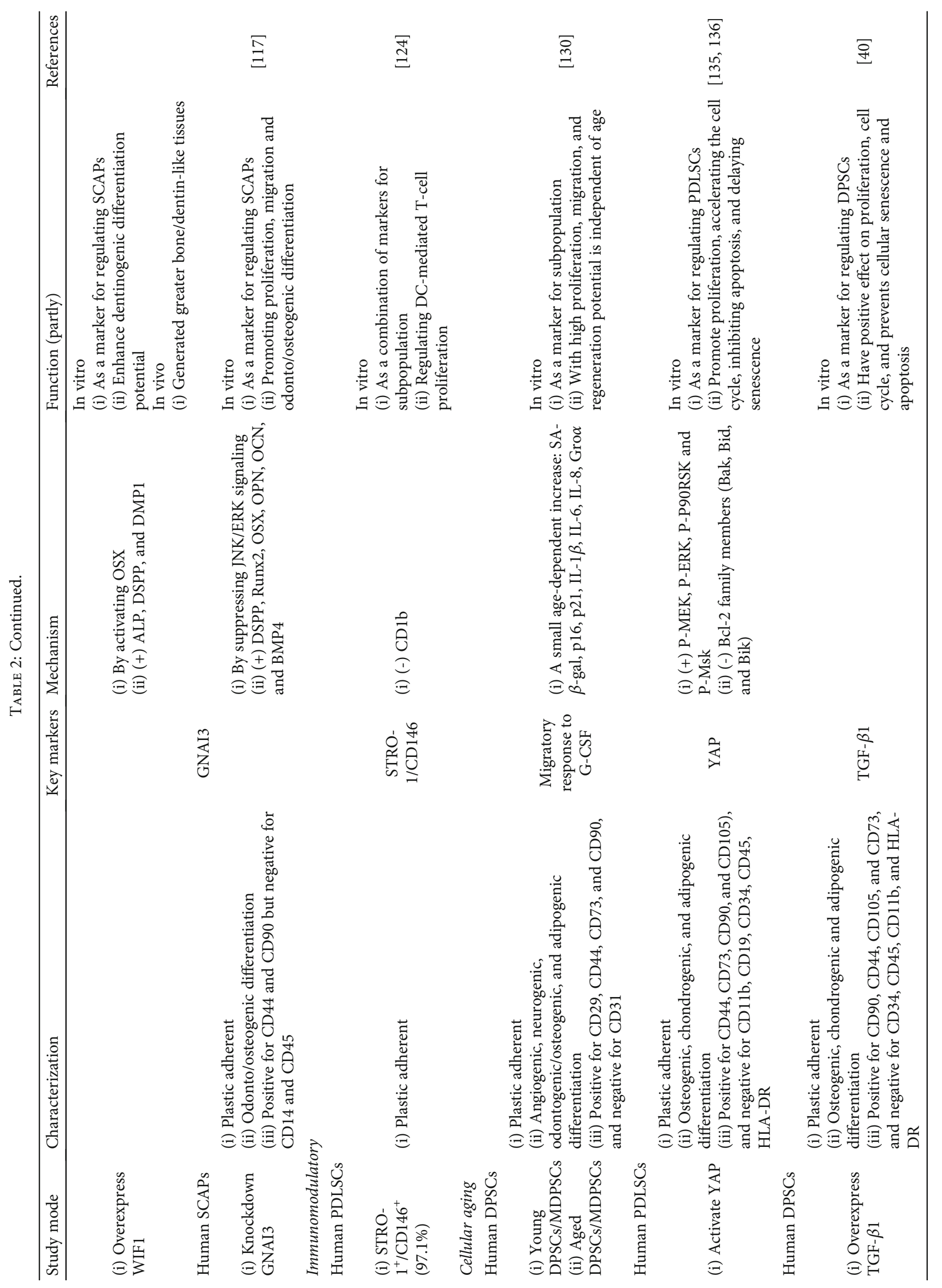


CD34 is a transmembrane phosphoglycoprotein that was discovered for the first time in hematopoietic stromal cells (SCs). Clinically, it is related to the selection and enrichment of hematopoietic SCs during bone marrow transplantation $[104,105]$. In addition, CD34 is assumed to act as a negative marker for MSCs [49]. Pisciotta et al. found that STRO $-1^{+} / \mathrm{c}-$ $\mathrm{Kit}^{+} / \mathrm{CD} 34^{+}$DPSCs showed a much higher efficiency of commitment compared to STRO- $1^{+} / \mathrm{c}-\mathrm{Kit}^{+} / \mathrm{CD} 34^{-}$DPSCs, which was demonstrated by the expression of $\beta$-III tubulin and the shift to a neuron-like shape following the induction [106]. Moreover, Carnevale et al. demonstrated that STRO- $1^{+} / \mathrm{c}-$ $\mathrm{Kit}^{+} / \mathrm{CD} 34^{+}$DPSCs expressed Schwann cell markers, such as p75NTR, glial fibrillary acidic protein (GFAP), and S100 calcium binding protein B (S100B), after incubation in appropriate induction media. The integration of the graft of the DPSCs-collagen scaffold complex into a sciatic nerve defect in rats contributed directly to nerve fiber regeneration and myelination in vivo [107].

Wnt inhibitory factor 1 (WIF1) belongs to a family of secreted modulators of Wnt proteins. A recent study suggested that WIF1 may enhance the dentinogenic differentiation potential in SCAPs via its regulation of OSX. Moreover, in vivo transplantation experiments revealed that dentinogenesis in SCAPs was enhanced by WIF1 overexpression [108]. Other members of the Wnt modulator family, including secreted frizzled-related proteins (sFRPs), play different roles in Wnt signaling depending on the cell subtype and model used [109-112]. Guanine nucleotide binding proteins (GNAIs) are a family of regulatory proteins responsible for molecular signal transduction of extracellular signals to the intracellular environment [113]. GNAI3 has been demonstrated to play a role in regulating various cellular processes, including proliferation, cytokinesis, apoptosis, migration, and invasion [114-116]. GNAI3 is primarily expressed in Hertwig's epithelial root sheath (HERS) and the surrounding mesenchyme in mice. Moreover, knockdown of GNAI3 could inhibit the proliferation, migration, and odonto/osteogenic differentiation of $\mathrm{CD} 90^{+} / \mathrm{CD} 44^{+} / \mathrm{CD} 45^{-} / \mathrm{CD} 14^{-}$SCAPs by inactivating c-Jun $\mathrm{N}$-terminal kinase (JNK) and extracellular-signal regulated kinase (ERK) signaling pathways [117].

3.3. Immunomodulatory Key Markers. MSCs-based immunomodulation may play an essential role in the regeneration of different tissues. The immunomodulatory and tropic capacity of transplanted MSCs contributes to the creation of a microenvironment that promotes the activation of endogenous tissue repair mechanisms, and it is now considered to be the major mechanism underlying the therapeutic effects of these cells in vivo [118]. Similar to MSCs from other tissues, dental-derived MSCs possess a strong immunomodulatory ability $[6,119,120]$. Potential mechanisms underlying the immunomodulatory effects of MSCs include enzyme expression, soluble factor production, and cell-tocell contact [121].

STRO $-1^{+}$cells in MSCs have significantly enhanced inhibitory effects on lymphocyte proliferation compared with STRO- $1^{-}$cells; thus, STRO- $1^{+}$cells impart stronger immunoregulatory effects than STRO- $1^{-}$cells $[122,123]$. A previous study showed that the STRO $-1^{+} \mathrm{CD} 146^{+}$subpopulation of PDLSCs inhibit $\mathrm{T}$ cell proliferation by suppressing the expression of the nonclassical major histocompatibility complex-like glycoprotein CD1b on dendritic cells [124]. The priming of dental-derived MSCs with interferon-gamma (IFN- $\gamma$ ), tumor necrosis factor- (TNF-) $\alpha$, and interleukin(IL-) $1 \beta$ usually enhances their immunosuppressive ability and could be considered a feedback mechanism that dampens exacerbated immune responses [121]. A recent study of human DPSCs showed that their ability to inhibit peripheral blood mononuclear cell (PBMC) proliferation and B cell immunoglobulin production was significantly enhanced by IFN- $\gamma$ and inhibited by anti-IFN- $\gamma$ antibodies [125].

3.4. Key Markers of Cellular Aging. MSCs aging is a negative process from the perspective of cell-based therapies because all advantageous functions may become limited with age. Dental-derived MSCs show clear losses in proliferation capacity with increasing donor age, and they also show donor age-related decreases in maximal life span and proliferation rate [126]. Under standard cell culture conditions, DFCs exhibit cellular senescence after being expanded by more than 14 cell passages [127]. With aging, the proliferation and osteogenic/adipogenic/chondrogenic differentiation potential of PDLSCs decreased while the apoptosis of PDLSCs increased. Moreover, the immunosuppressive ability of PDLSCs decreased with aging [128].

Signs of senescent cells include cell growth arrest, DNA damage foci, and senescence-associated $\beta$-galactosidase expression, and identifying these markers represents a reliable method for detecting senescent cells [129]. Horibe et al. isolated DPSCs subsets based on their migratory response to granulocyte colony stimulating factor (G-CSF) (MDPSCs) from young and aged donors. In long-term culture, MDPSCs showed a small age-dependent increase in senescence-associated $\beta$-galactosidase (SA- $\beta$-gal) production and senescence markers, including p16, p21, IL-1 $\beta$, IL-6, IL8 , and Gro $\alpha$. The regenerative potential of aged MDPSCs was similar to that of young MDPSCs in an ischemic hindlimb model and an ectopic tooth root model [130]. Autologous transplantation of MDPSCs with G-CSF in pulp-ectomized teeth in dogs augmented the regeneration of pulp tissue. Furthermore, MDPSCs from aged donors were as potent as those from young donors [131]. Notably, MDPSCs showed no significant age-related changes in biological properties, such as stability, regenerative potential, and senescence marker expression.

The Hippo pathway is a newly discovered signaling network that is evolutionarily and functionally conserved and has been shown to play a critical role in controlling organ size by regulating both cell proliferation and apoptosis [132, 133]. As a Hippo signaling transcriptional coactivator, YAP plays pivotal roles in MSCs fate and organ size control [134]. Jia et al. discovered that activated YAP promotes proliferation, accelerates the cell cycle, inhibits apoptosis, and delays senescence in human PDLSCs [135]. Knockdown of YAP inhibits the proliferation activity and induces apoptosis of human PDLSCs with the involvement of the Hippo pathway and shows crosstalk with the Erk and Bcl-2 signaling pathways 
[136]. Transforming growth factor- (TGF-) $\beta 1$ is a potent stimulator of tissue regeneration and is abundant in the bone matrix [137]. Salkin et al. found that TGF- $\beta 1$ transfection has a positive effect on proliferation and the cell cycle and prevents cellular senescence and apoptosis. They suggested that TGF- $\beta 1$ overexpression with gene transfer may improve the biological potential of DPSCs and could represent an option instead of transmission of recombinant protein into cells from the outside [40]. However, the effects of TGF- $\beta 1$ associated with cell senescence are controversial. A previous study demonstrated that treatment with TGF- $\beta 1$ induced PDLSCs senescence, which is characterized by increasing in senescence-associated $\beta$-galactosidase activity and both p16 and p21 expression. Furthermore, TGF- $\beta 1$ treatment demonstrated the capacity to induce the production of reactive oxygen species (ROS). Of note, the addition of a ROS scavenger successfully rescued TGF- $\beta 1$-induced PDLSCs senescence [138]. These results indicated that the regulatory mechanism of TGF- $\beta 1$ in cell senescence is quite different in various cells.

\section{Epigenetic Modifications in Dental- Derived MSCs}

Epigenetic modifications regulate gene expression without changing the DNA sequence and affect cell development and differentiation. DNA methylation, histone posttranslational modification, and noncoding RNA play primary roles in epigenetic mechanisms [139]. The rescuing potential of MSCs is under the control of different kinds of signals, including the environment, which epigenetically regulate their differentiation processes [140]. Recently, the epigenetic modifications that regulate dental-derived MSCs were revealed; thus, the use of epigenetics to improve the therapeutic potential of dental-derived MSCs has been highlighted. Therefore, summarizing these multiple epigenetic modifications associated with the differentiation process and determining how these modifications could be reversed are of paramount importance. Table 3 lists some epigenetic biological targets in the field of dental-derived MSCs.

4.1. DNA Methylation. DNA methylation is an essential epigenetic mechanism that plays a vital role in the development and differentiation of early embryos by regulating gene expression patterns. The global DNA methylation landscapes of early-life human tissues, such as oocytes, blastocysts, or placenta, are characterized by specific genome-wide hypomethylation compared to differentiated tissue postimplantation [141]. A previous study found that SHEDs have partially methylated domains (PMDs) that are close to the inner cell mass (ICM) and placental methylome. The methylation status of related genes changes under inflammation. For example, $44 \%$ of normal dental pulp tissues show complete methylation, while $93 \%$ of inflamed dental pulp tissue samples contain IFN- $\gamma$ genes that are only partially methylated or unmethylated. In addition, IFN- $\gamma$ transcription does not occur in the pulp tissue that shows per-methylation [142].
DNA methylation refers to the process in which methyl groups are transferred to cytosine bases of DNA and converted into 5-methylcytosine [143]. This process is catalyzed by DNA methyltransferases (DNMTs). The DNA methyltransferase family includes DNMT1, DNMT2, DNMT3a, DNMT3b, and DNMT3L. Several studies suggest that DNA demethylation levels are correlated with the osteogenesis capacity of MSCs and that DNMT inhibitors could downregulate DNA methylation to improve osteogenesis [144, 145]. 5-Azacytidine (5-aza), a DNMT inhibitor, works by integrating into the DNA structure to prevent DNA from interacting with DNMTs, and it also stimulates DNMT degradation [146]. Liu et al. found that high glucose conditions increased the DNA methylation levels of PDLSCs and blocked osteogenic differentiation ability. 5-Aza-2' -deoxycytidine (5-aza$\mathrm{dC}$ ) could rescue the osteogenic differentiation capacity of PDLSCs through activation of the canonical Wnt signaling pathway and the upregulation of osteogenesis-related genes (ALP, OCN, osteopontin (OPN), and OSX) [147]. Upon treatment with 5-aza- $2^{\prime}$-deoxycytidine (5-aza-CdR), the odontogenic differentiation capacity of DPSCs is enhanced. 5-Aza-CdR upregulates odontogenic markers (DSPP and DMP1) and transcription factors (RUNX2, DLX5, and OSX), increases ALP activity, and accelerates calcified nodule formation [148]. In addition, myogenic differentiation is also improved after treatment with 5-aza. Nakatsuka et al. used 5aza to investigate the myogenic differentiation potential of mouse DPSCs. DNA demethylation induced by 5 -aza and forced expression of myogenic differentiation 1 (Myod1) upregulated muscle-specific transcription factors, such as myogenin and paired box 7 (Pax7) [149].

The ten-eleven translocation (Tet) family is a group of recently identified demethylases capable of modifying DNA by hydroxylating 5-methylcytosine $(5-\mathrm{mC})$ to 5 hydroxymethylcytosine $(5-\mathrm{hmC})$ [150]. Three Tet family members (Tet1, Tet2, and Tet3) show distinct expression patterns depending on the cell or tissue type and developmental stage $[151,152]$. This discovery revealed a new mechanism by which the Tet enzyme regulates DNA demethylation. Yu et al. found that downregulation of Tet1 and Tet2 led to the hypermethylation of the Dickkopf WNT signaling pathway inhibitor 1 (DKK-1) promoter, activated the WNT signaling pathway, and increased the expression of FasL, and it also improved the immune regulation ability of PDLSCs. Importantly, Tet1/Tet2-downregulated PDLSCs showed a significantly increased therapeutic effect on DSS-induced colitis mice [153]. This result indicated that the Tet/DKK-1/FasL cascade may serve as a promising target for enhancing PDLSCs-based immune therapy.

4.2. Histone Posttranslational Modifications. The posttranslational modification of histones mainly occurs at the $\mathrm{N}$-end of the tail protruding from the nucleosome core, and this modification plays an essential role in chromatin remodeling and gene expression regulation. In detail, distinct histone aminoterminal modifications can generate synergistic or antagonistic interaction affinity for chromatin-associated proteins, which in turn dictate dynamic transitions between transcriptionally active or transcriptionally silent chromatin states 


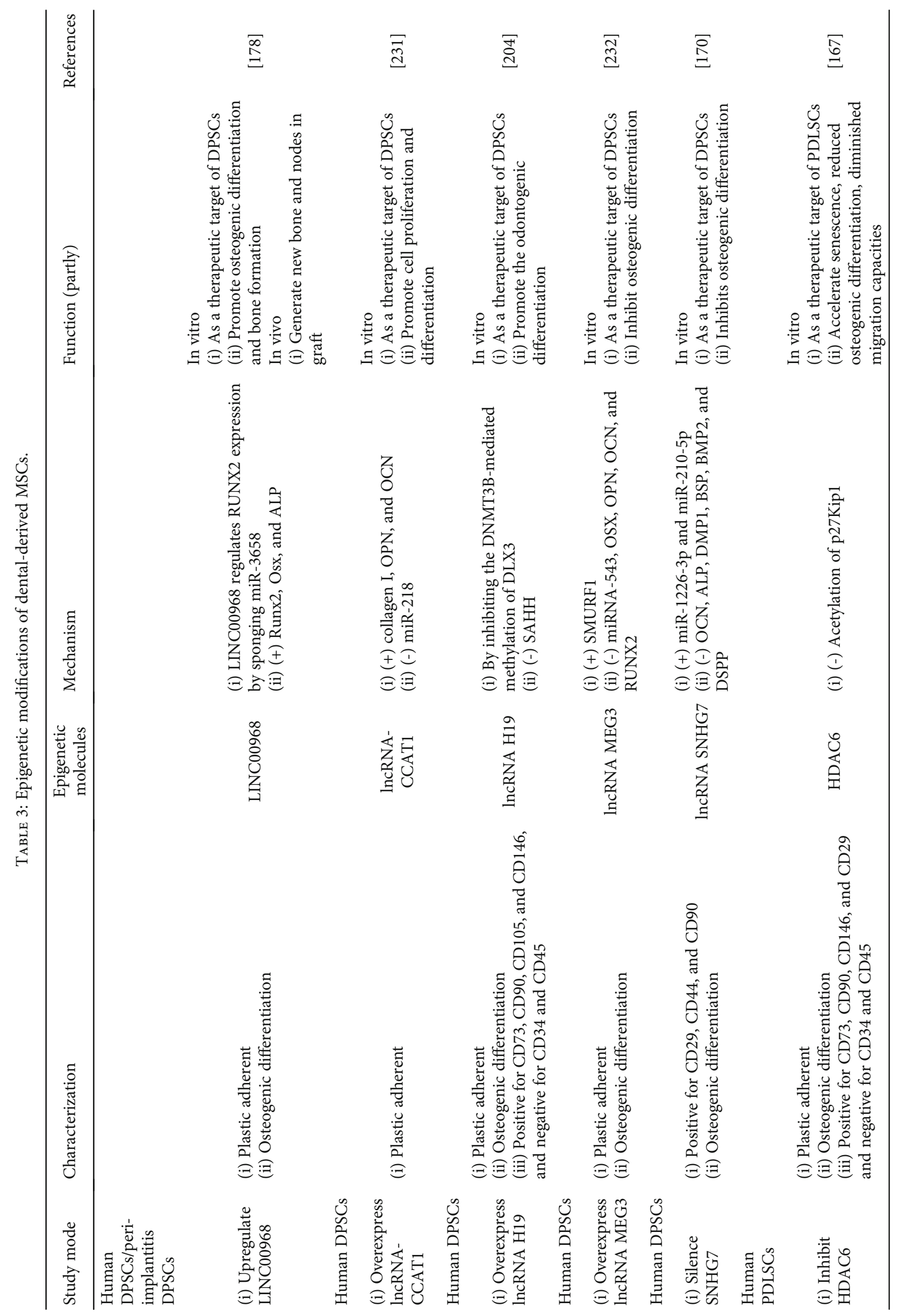




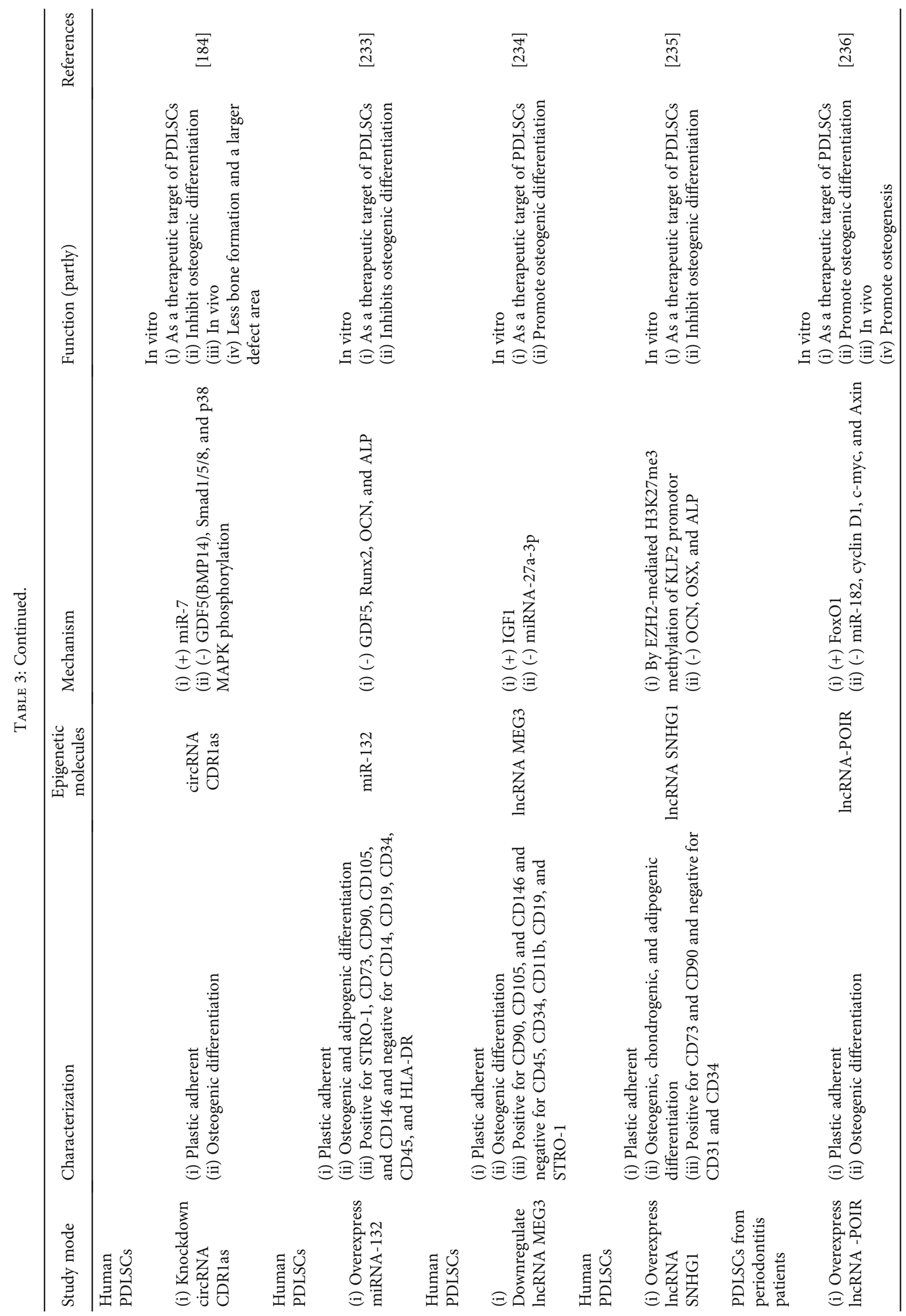




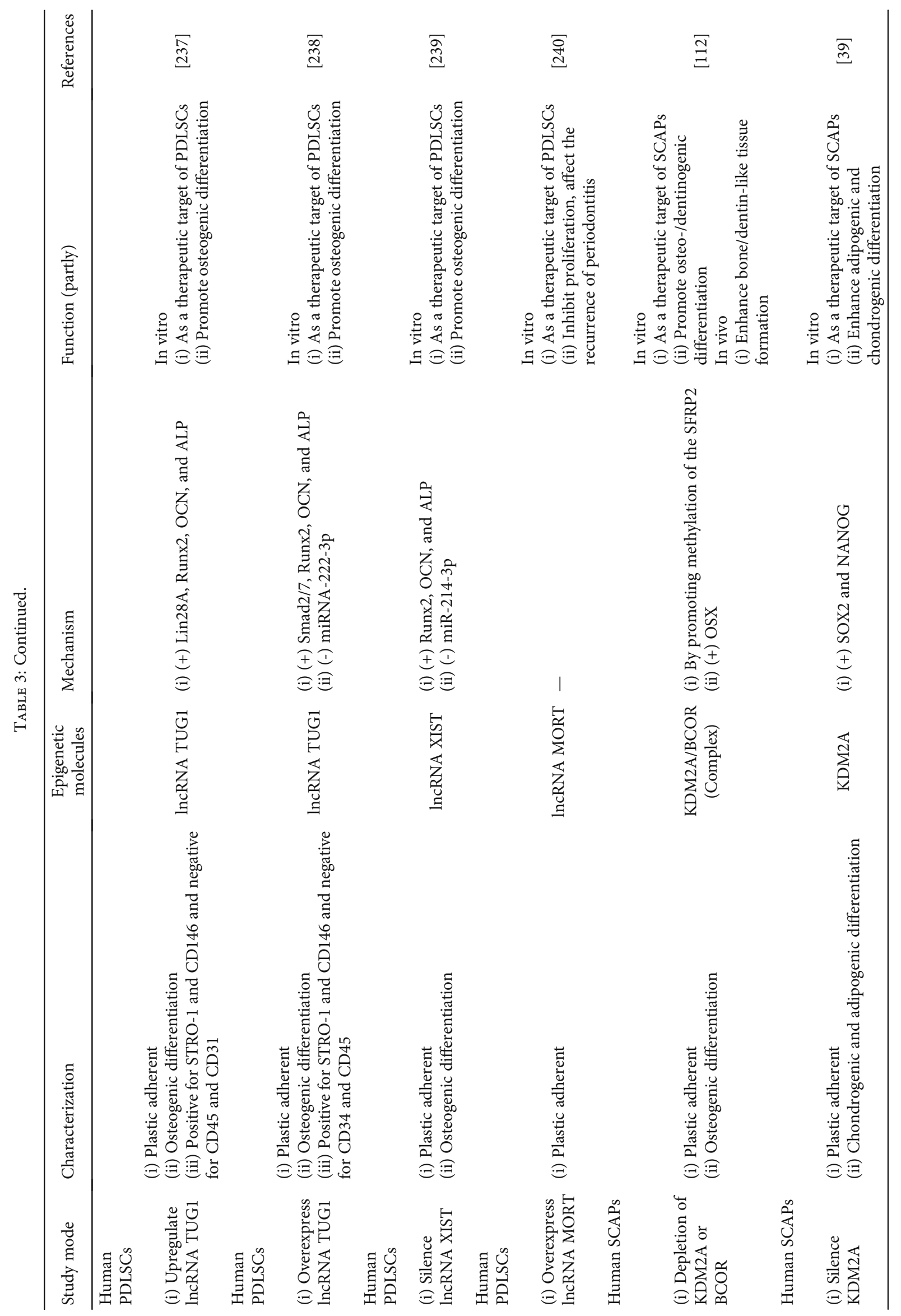




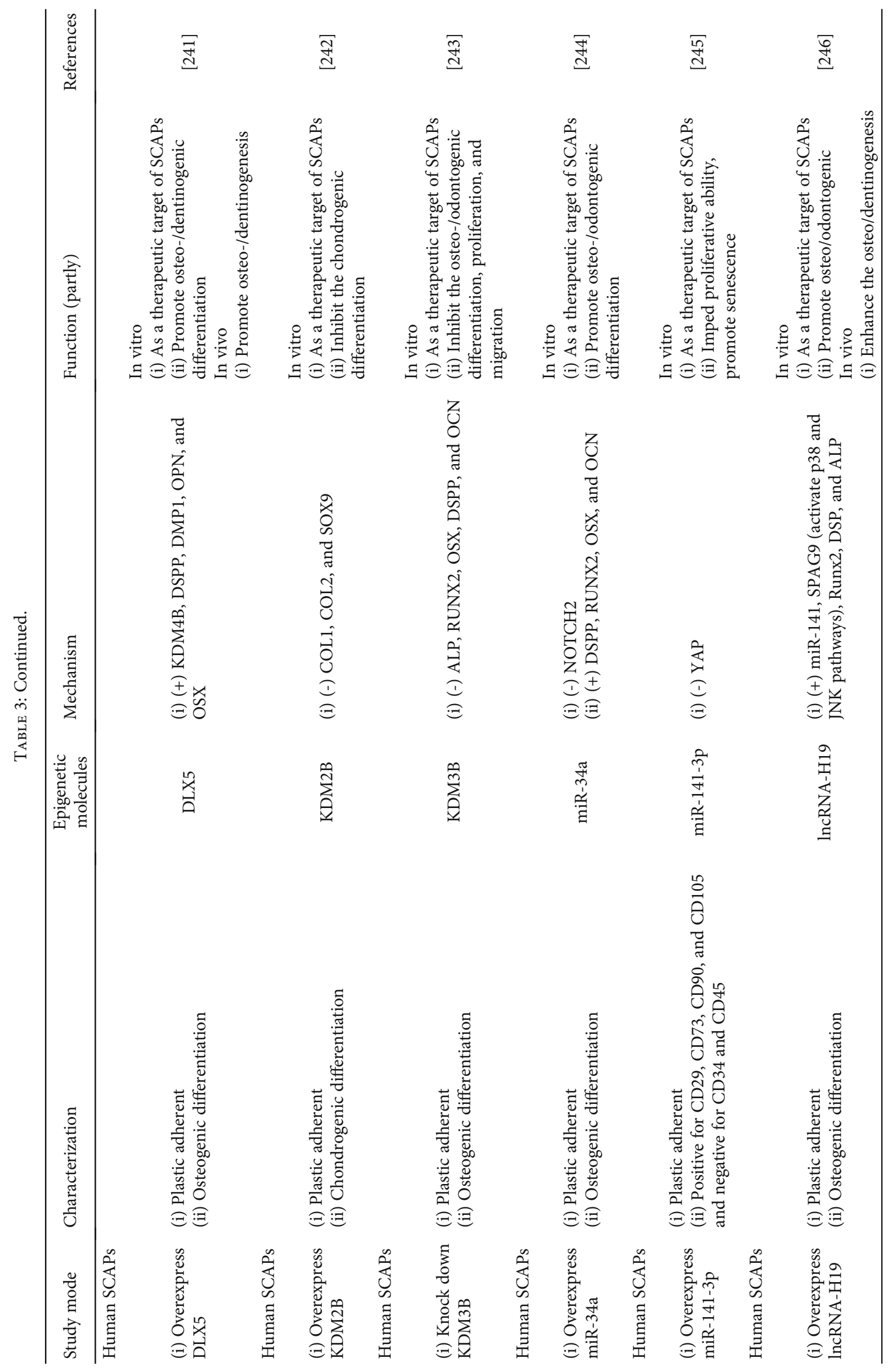




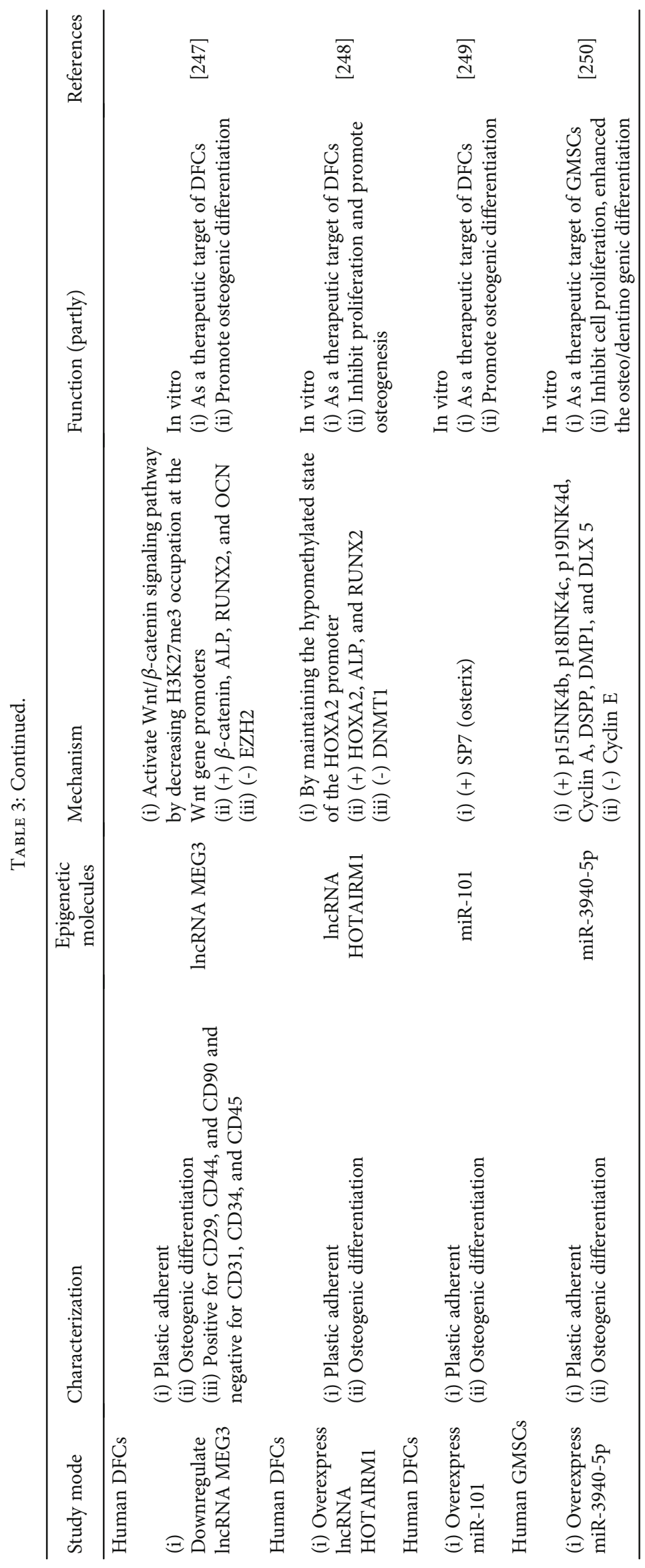


[154]. The more common histone modifications include methylation, acetylation, phosphorylation, and ubiquitination. Among them, histone acetylation has been widely studied in the field of dental-derived MSCs [155]. Acetylation is the only modification that directly causes a structural relaxation of chromatin by neutralizing the charge of histones [156]. The balance of the acetylation process depends on the role of histone acetyltransferases (HATs) and histone deacetylases (HDACs). HATs cause histidine acetyltransferases to add negatively charged acetyl groups, which weaken the interaction between DNA and histone residues, while HDACs remove acetyl groups [157].

The vital role of the acetylation process in maintaining the balance between osteoblastic bone formation and osteoclastic bone resorption is crucial for bone tissue homeostasis [158]. The acetylation of H3K14 (histone H3, lysine 14) and H3K9 (histone H3, lysine 9) can promote osteogenic differentiation of dental-derived MSCs [159]. HDACs are downregulated during the osteogenic differentiation of dentalderived MSCs [160, 161]. The use of HDAC inhibitors effectively increases the acetylation of H3K9K14 (histone H3, lysines 9 and 14) and promotes the expression of bonerelated genes [162, 163]. Valproic acid (VPA), a short-chain fatty acid, can inhibit class II HDACs. Paino et al. demonstrated that HDAC2 silencing in DPSCs leads to increased expression of OPN and bone sialoprotein (BSP) and downregulates the mRNA levels of osteocalcin $(\mathrm{OCN})$, which resembles the effect of VPA [164]. This result suggests that the specific inhibition of an individual HDAC by RNA interference could only enhance a single aspect of osteoblast differentiation, resulting in selective effects. It has been reported that the glucocorticoid receptor (GR) plays a key role in this regulation. HDAC2 binds to GR and inhibits its translocation into the nucleus; however, when HDAC2 is inhibited by VPA, GR can enter the nucleus, thereby affecting the expression of OCN [165].

Histone deacetylase 6 (HDAC6) is a class IIb HDAC with a unique duplicated deacetylase domain and ubiquitinbinding domain [166]. Interestingly, HDAC6, as a critical regulator of PDLSCs aging, can deacetylate p27Kip1. Lossof-function experiments suggested that pharmacologic inhibition of the deacetylase activity of HDAC6 accelerated PDLSCs senescence and impaired MSCs activities, which showed reduced osteogenic differentiation and diminished migration capacities; thus, HDAC6 may be a new target for intervention in the aging process of PDLSCs [167].

4.3. Noncoding RNAs. Noncoding RNAs (ncRNAs) play an essential role in histone modification, gene silencing, and targeting DNA methylation. They are divided into short ncRNAs, with lengths of less than 30 nucleotides, and long ncRNAs, with more than 200 nucleotides [168]. ncRNAs regulate gene expression through transcription and posttranscriptional control. The overall activity and functional balance of gene networks are maintained by $\operatorname{lncRNA} / \mathrm{miR}$ NA/mRNA regulatory interactions [169]. For example, a total of $89 \operatorname{lncRNAs}, 1,636$ mRNAs, and 113 miRNAs were differentially expressed after DPSCs differentiation. Simultaneously, an array of signaling pathways, including phosphoinositide-3-kinase-protein kinase B, TGF- $\beta$, and Wnt, were also affected. The lncRNA SNHG7 was shown to inhibit the odonto/osteogenic differentiation of DPSCs when silenced [170].

MicroRNAs (miRNAs) are vital regulators that promote the intrinsic properties of MSCs, such as their self-renewal, pluripotency, and differentiation capacities, and miRNAs have a length of approximately 20-22 nucleotides. MiRNAs extensively regulate cell functions by affecting the abundance and translation efficiency of homologous mRNAs. Single miRNAs can target numerous gene sites on mRNA transcripts. In contrast, targeting multiple miRNAs can jointly target a single mRNA [171-173]. MiRNAs are believed to be novel regulators in the differentiation of dental MSCs by targeting related genes. During osteogenic differentiation, the expression of 116 miRNAs was altered significantly in PDLSCs. The upregulated miRNAs were miR-654-3p and miR-4288 and the downregulated miRNAs were miR-34c5p, miR-218-5p, miR-663a, and miR-874-3p. The prediction of target genes suggested that these significantly altered miRNAs may impact the osteogenic differentiation of PDLSCs by targeting osteogenesis-related genes [174].

Long noncoding RNAs (lncRNAs) (>200 nucleotides) are the largest ncRNA transcript family in the human genome and participate in transcription and posttranscriptional and epigenetic regulation of genes [175]. lncRNAs can fold into complex secondary or higher-order structures, and they show greater potential and versatility for gene regulation than miRNAs [176]. lncRNAs can act as RNA decoys and miRNA target site decoys. They bind to specific combinations of regulatory proteins and play essential roles in chromatin modification and processing of mRNA targets. A recent study showed that IncRNAs can cross-talk with mRNAs through competition for shared miRNA-response elements. In this circumstance, IncRNAs function as competitive endogenous RNAs (ceRNAs), which correspond to miRNA sponges or antagomirs, to affect the expression levels and activities of miRNAs, thereby repressing miRNA targets and causing an additional level of posttranscriptional regulation [177]. Previous studies have shown that lncRNAs regulate gene expression and function by competing with miRNAs for binding to target mRNAs [178]. Two thousand and one hundred sixty-two lncRNAs were differentially expressed between PDLSCs and GMSCs. These lncRNAs could be potential regulators, especially those with higher fold change (FC), such as lncRNA-n336841, IncRNAn341766, and lncRNA-n333720 [179].

Circular RNAs (circRNAs) are widely distributed in organisms and represent a type of ncRNA with a cyclic covalent structure that has a high degree of evolutionary conservation and tissue cell expression specificity [180, 181]. circRNAs are more stable than linear RNAs due to their resistance to ribonuclease digestion [182]. Chen et al. revealed the circRNA expression profile in DPSCs during odontogenic differentiation. 43 upregulated circRNAs and 144 downregulated circRNAs were found in the process of dental differentiation. These differentially expressed genes are rich in signaling pathways that regulate the pluripotency of MSCs, such as the Wnt signaling pathway and the TGF 
signaling pathway [183]. Recently, circRNAs were also shown to function as ceRNAs to regulate the effect of miRNAs on their target genes during cell differentiation. Previous studies have found that circRNA cerebellar degenerationrelated protein 1 (CDR1) competitively inhibits miR-7 and stimulates the expression of growth differentiation factor(GDF-) 5, thereby promoting the osteogenic differentiation of PDLSCs. This process activates the Smad1/5/8 and p38 MAPK differentiation pathways [184]. In addition, CDR1as acted as a miR-7 sponge to activate the ERK signaling pathway and thus mediated the inhibitory effect of lipopolysaccharide (LPS) on cell proliferation. Knockdown of CDR1as promotes the inhibition of PDLSCs proliferation induced by LPS [185].

\section{Conclusions}

Among the regenerative strategies, dental-derived MSCsbased techniques have demonstrated particular promise $[186,187]$. Several preclinical studies and clinical trials have been performed using dental-derived MSCs for the treatment of dental and nondental diseases, such as neurodegenerative diseases and autoimmune and orthopedic disorders [188191]. Moreover, no adverse events that may be related to cell transplantation have been reported $[192,193]$. These suggest the efficacy and safety of dental-derived MSCs-based therapy. However, previous studies have illustrated the difficulty in generating a consistent population of cells for therapeutic use. Even with tissue from a single donor, controlled culture conditions, and the expansion of single cells, each clone produces a distinct population with widely different morphology, growth kinetics, gene expression profile, and epigenetic status [194-196]. Based on this, we could consider that it may be necessary in the future to establish MSCs banks based on the heterogeneity of dental-derived MSCs, in case of a need to screen for cells prior to clinical use [12].

In addition, clonal cultures serve as an extremely useful research tool to identify desirable properties of cells within mixed populations. In future studies, screening of single cellderived clones on a larger scale to that described in this report will serve to further understand cell heterogeneity and its impact on the development of MSCs-based therapies [50]. We recommend that, whenever possible, studies performed at the population level should be validated in terms of the principal findings using clonally expanded populations. This would clarify whether the response is common to all MSCs, or only to selected subpopulations [22]. Moreover, functional diversity within a MSCs colony must be considered in the design of experiments and trials for even nonclonal MSCs populations and can be mitigated or even exploited when the mechanisms of onset are better understood.

Cell therapy entails the administration of living cells that have been purified, propagated, or differentiated to create a cell product for a specific therapeutic need [197]. Identifying key markers that support cell functions is a significant aspect of the development of dental-derived MSCs therapies. It allows the optimization of population selection by selectively screening and isolating better quality dental-derived MSCs for in vitro expansion and assessment, aiding the transla- tional development of more effective MSCs-based therapies for clinical evaluation and application [76]. Strategies to isolate, purify, and propagate subpopulations of adult MSCs may, therefore, contribute to the development of cell therapy products with enhanced clinical benefit in the future. Moreover, cell reprogramming and the induction of pluripotency depend critically on the control of the epigenetic tags linked to cell differentiation [198]. Therefore, the study of these multiple epigenetic modifications associated with the differentiation process, and how these could be reversed, is of paramount importance $[25,140,199]$. The ideal situation is when key markers of dental-derived MSCs could be analyzed and used to identify different cell types or subpopulations in the complex tissue [200]. The epigenome information from the same set of single cells could be used subsequently to investigate how different epigenetic layers regulate transcription [201]. Finally, to build a causal relationship between genotype and phenotype, it will be ideal to knock out key component genes for MSCs in vivo using gene-editing technologies [202, 203]. This control over dental-derived MSCs composition and function will accelerate the translation of cell therapy into clinical practice.

Although the results of the present research on dentalderived MSCs are promising, many of the key markers and epigenetic modifications discussed here have yet to be validated in an animal model $[81,89,204]$. There are currently less clinical research reports on dental-derived MSCs. A key challenge in therapeutic application of MSCs appears to be that the surface markers commonly related to in vitro functionality are not necessarily associated with the corresponding activity in vivo [205]. Based on this, we encourage verifying first in animal models and then in clinical trials all the promising surface markers and epigenetic modifications that have been identified based on the in vitro function of MSCs. Key molecules that are predictive of clinical outcome are candidates to use as quality attributes for robust and reproducible manufacturing of MSCs therapies [20, 206, 207]. Moreover, clinicians need to be encouraged to pay more attention to the research progress of dental-derived MSCs and develop new methods for clinical application. Small advances in the clinical application of dental-derived MSCs will bring great encouragement to researchers [208210]. Similarly, the development of basic research will accelerate the clinical application of dental-derived MSCs [211, 212].

\section{Abbreviations}

MSCs: Mesenchymal stromal cells

SCs: $\quad$ Stromal cells

BMMSCs: Bone marrow mesenchymal stromal cells

DPSCs: Mesenchymal stromal cells of dental pulp

SCAPs: Mesenchymal stromal cells of apical papilla

SHEDs: Mesenchymal stromal cells of human exfoliated deciduous teeth

PDLSCs: Mesenchymal stromal cells of periodontal ligament

DFCs: Dental follicle cells

GMSCs: Mesenchymal stromal cells of gingiva 
TGSCs: Mesenchymal stromal cells of human tooth germ

FASL: $\quad$ Fas-ligand

N-GMSCs: Cranial neural crest cell-derived GMSCs

M-GMSCs: Mesoderm GMSCs

YAP1: $\quad$ Yes-associated protein 1

PD: $\quad$ Population doublings

Map2: $\quad$ Microtubule-associated protein 2

NF: $\quad$ Neurofilament

OCT-4: Octamer-binding transcription factor-4

SSEA-3: $\quad$ Stage-specific embryonic antigen-3

iPS: $\quad$ Pluripotent stromal

ES: $\quad$ Embryonic stromal

PGCs: Primordial germ cells

ALP: $\quad$ Alkaline phosphatase

SOX2: $\quad$ Sex-determining region Y-box-2

NFIC: $\quad$ Nuclear factor I-C

DMP1: Dentin matrix protein-1

DSPP: Dentin sialophosphoprotein

NTR: $\quad$ Neurotrophin receptor

SVZ: $\quad$ Subventricular zone

SGZ: $\quad$ Subgranular zone

DLX5: Distal-less homeobox 5

BGLAP: Bone gamma-carboxyglutamate protein

GFAP: Glial fibrillary acidic protein

S100B: $\quad$ S100 calcium binding protein B

WIF1: Wnt inhibitory factor 1

SFRPs: $\quad$ Secreted frizzled-related proteins

GNAIs: Guanine nucleotide binding proteins

HERS: Hertwig's epithelial root sheath

JNK: $\quad$ c-Jun N-terminal kinase

ERK: $\quad$ Extracellular-signal regulated kinase

IFN- $\gamma$ : Interferon-gamma

PBMC: $\quad$ Peripheral blood mononuclear cell

G-CSF: Granulocyte colony stimulating factor

MDPSCs: DPSC subsets based on their migratory response to G-CSF

SA- $\beta$-gal: $\quad$ Senescence-associated $\beta$-galactosidase

CFU: $\quad$ Colony-forming unit

OCT-4: Octamer-binding transcription factor-4

IL-1 $\beta$ : Interleukin-1 $\beta$

TGF- $\beta 1$ : Transforming growth factor- $\beta 1$

ROS: $\quad$ Reactive oxygen species

PMDs: $\quad$ Partially methylated domains

ICM: Inner cell mass

DNMTs: DNA methyltransferases

5-Aza: 5-Azacytidine

5-Aza-dC: 5-Aza-2'-deoxycytidine

5-aza-CdR: 5-Aza-2'-deoxycytidine

OPN: Osteopontin

Pax7: $\quad$ Paired box 7

Myod1: Myogenic differentiation 1

Tet: $\quad$ Ten-eleven translocation

5-Mc: 5-Methylcytosine

5-hmC: 5-Hydroxymethylcytosine

DKK-1: $\quad$ Dickkopf WNT signaling pathway inhibitor 1

HATs: Histone acetyltransferases

HDACs: Histone deacetylases

H3K14: $\quad$ Histone H3, lysine 14
H3K9: $\quad$ Histone H3, lysine 9

H3K9K14: Histone H3, lysines 9 and 14

VPA: $\quad$ Valproic acid

BSP: $\quad$ Bone sialoprotein

OCN: Osteocalcin

GR: $\quad$ Glucocorticoid receptor

HDAC6: Histone deacetylase 6

ncRNAs: Noncoding RNAs

miRNAs: MicroRNAs

lncRNAs: Long noncoding RNAs

ceRNAs: Competitive endogenous RNAs

circRNAs: Circular RNAs

FC: $\quad$ Fold change

CDR1: Cerebellar degeneration-related protein 1

GDF: $\quad$ Growth differentiation factor

SFRPs: $\quad$ Secreted frizzled-related proteins.

\section{Conflicts of Interest}

The authors declare that they have no competing interests.

\section{Acknowledgments}

This study is supported by grants from the Scientific Research Fund Project of Yunnan Provincial Department of Education (No. 220J0213) and the Yunnan Provincial Science and Technology Department-Kunming Medical University Applied Basic Research Joint Special Fund (No. 202001AY070001-151).

\section{References}

[1] O. F. Gardner, M. Alini, and M. J. Stoddart, "Mesenchymal stem cells derived from human bone marrow," Cartilage Tissue Engineering, vol. 1340, pp. 41-52, 2015.

[2] E. R. Chiang, H. L. Ma, J. P. Wang, C. L. Liu, T. H. Chen, and S. C. Hung, "Multi-lineage differentiation and angiogenesis potentials of pigmented villonodular synovitis derived mesenchymal stem cells-pathological implication," Journal of Orthopaedic Research, vol. 34, no. 3, pp. 395-403, 2016.

[3] H. Ohgushi, "Osteogenically differentiated mesenchymal stem cells and ceramics for bone tissue engineering," Expert Opinion on Biological Therapy, vol. 14, no. 2, pp. 197-208, 2014.

[4] T. Seeger, M. Hart, M. Patarroyo, B. Rolauffs, W. K. Aicher, and G. Klein, "Mesenchymal stromal cells for sphincter regeneration: role of laminin isoforms upon myogenic differentiation," PLoS One, vol. 10, no. 9, article e0137419, 2015.

[5] G. R. Fajardo-Orduña, H. Mayani, P. Flores-Guzmán et al., "Human mesenchymal stem/stromal cells from umbilical cord blood and placenta exhibit similar capacities to promote expansion of hematopoietic progenitor cells in vitro," Stem Cells International, vol. 2017, Article ID 6061729, 9 pages, 2017.

[6] S. Ceccarelli, P. Pontecorvi, E. Anastasiadou, C. Napoli, and C. Marchese, "Immunomodulatory effect of adipose-derived stem cells: the cutting edge of clinical application," Frontiers in Cell and Development Biology, vol. 8, p. 236, 2020.

[7] D. B. Sequeira, A. R. Oliveira, C. M. Seabra et al., "Regeneration of pulp-dentin complex using human stem cells of the 
apical papilla: in vivo interaction with two bioactive materials," Clinical Oral Investigations, 2021.

[8] C. P. Panduwawala, X. Zhan, W. L. Dissanayaka, L. P. Samaranayake, L. Jin, and C. Zhang, "In vivo periodontal tissue regeneration by periodontal ligament stem cells and endothelial cells in three-dimensional cell sheet constructs," Journal of Periodontal Research, vol. 52, no. 3, pp. 408-418, 2017.

[9] U. Kandalam, T. Kawai, G. Ravindran et al., "Predifferentiated gingival stem cell-induced bone regeneration in rat alveolar bone defect model," Tissue Engineering. Part A, vol. 27, no. 5-6, pp. 424-436, 2021.

[10] A. Bajek, M. Czerwinski, J. Olkowska, N. Gurtowska, T. Kloskowski, and T. Drewa, "Does aging of mesenchymal stem cells limit their potential application in clinical practice?," Aging Clinical and Experimental Research, vol. 24, no. 5, pp. 404-411, 2012.

[11] M. Ducret, H. Fabre, O. Degoul et al., "Immunophenotyping reveals the diversity of human dental pulp mesenchymal stromal cells in vivo and their evolution upon in vitro amplification," Frontiers in Physiology, vol. 7, p. 512, 2016.

[12] W. Wang and Z. C. Han, "Heterogeneity of human mesenchymal stromal/stem cells," Advances in Experimental Medicine and Biology, vol. 1123, pp. 165-177, 2019.

[13] S. Gronthos, J. Brahim, W. Li et al., "Stem cell properties of human dental pulp stem cells," Journal of Dental Research, vol. 81, no. 8, pp. 531-535, 2002.

[14] S. Ranga Rao and R. Subbarayan, "Passage-dependent expression of STRO-1 in human gingival mesenchymal stem cells," Journal of Cellular Biochemistry, vol. 120, no. 3, pp. 28102815, 2019.

[15] R. Alvarez, H. L. Lee, C. Y. Wang, and C. Hong, "Characterization of the osteogenic potential of mesenchymal stem cells from human periodontal ligament based on cell surface markers," International Journal of Oral Science, vol. 7, no. 4, pp. 213-219, 2015.

[16] L. L. Zhou, W. Liu, Y. M. Wu, W. L. Sun, C. E. Dörfer, and K. M. Fawzy el-Sayed, "Oral mesenchymal stem/progenitor cells: the immunomodulatory masters," Stem Cells International, vol. 2020, Article ID 1327405, 16 pages, 2020.

[17] T. Squillaro, G. Peluso, and U. Galderisi, "Clinical trials with mesenchymal stem cells: an update," Cell Transplantation, vol. 25, no. 5, pp. 829-848, 2016.

[18] S. Dimmeler, S. Ding, T. A. Rando, and A. Trounson, "Translational strategies and challenges in regenerative medicine," Nature Medicine, vol. 20, no. 8, pp. 814-821, 2014.

[19] D. J. Prockop, S. E. Prockop, and I. Bertoncello, "Are clinical trials with mesenchymal stem/progenitor cells too far ahead of the science? Lessons from experimental hematology," Stem Cells, vol. 32, no. 12, pp. 3055-3061, 2014.

[20] K. C. O'Connor, "Molecular profiles of cell-to-cell variation in the regenerative potential of mesenchymal stromal cells," Stem Cells International, vol. 2019, Article ID 5924878, 14 pages, 2019.

[21] V. W. Yu and D. T. Scadden, "Heterogeneity of the bone marrow niche," Current Opinion in Hematology, vol. 23, no. 4, pp. 331-338, 2016.

[22] D. A. Rennerfeldt and K. J. Van Vliet, "Concise review. When colonies are not clones: evidence and implications of intracolony heterogeneity in mesenchymal stem cells," Stem Cells, vol. 34 , no. 5 , pp. $1135-1141,2016$.
[23] K. C. Russell, M. R. Lacey, J. K. Gilliam, H. A. Tucker, D. G. Phinney, and K. C. O'Connor, "Clonal analysis of the proliferation potential of human bone marrow mesenchymal stem cells as a function of potency," Biotechnology and Bioengineering, vol. 108, no. 11, pp. 2716-2726, 2011.

[24] P. Deng, Q. M. Chen, C. Hong, and C. Y. Wang, "Histone methyltransferases and demethylases: regulators in balancing osteogenic and adipogenic differentiation of mesenchymal stem cells," International Journal of Oral Science, vol. 7, no. 4, pp. 197-204, 2015.

[25] L. Rinaldi and S. A. Benitah, "Epigenetic regulation of adult stem cell function," The FEBS Journal, vol. 282, no. 9, pp. 1589-1604, 2015.

[26] T. Kobayashi, D. Torii, T. Iwata, Y. Izumi, M. Nasu, and T. W. Tsutsui, "Characterization of proliferation, differentiation potential, and gene expression among clonal cultures of human dental pulp cells," Human Cell, vol. 33, no. 3, pp. 490-501, 2020.

[27] F. Wei, T. Song, G. Ding et al., "Functional tooth restoration by allogeneic mesenchymal stem cell-based bio-root regeneration in swine," Stem Cells and Development, vol. 22, no. 12, pp. 1752-1762, 2013.

[28] M. Miura, S. Gronthos, M. Zhao et al., "SHED: stem cells from human exfoliated deciduous teeth," Proceedings of the National Academy of Sciences of the United States of America, vol. 100, no. 10, pp. 5807-5812, 2003.

[29] F. M. Chen, H. H. Sun, H. Lu, and Q. Yu, "Stem cell-delivery therapeutics for periodontal tissue regeneration," Biomaterials, vol. 33, no. 27, pp. 6320-6344, 2012.

[30] W. Guo, K. Gong, H. Shi et al., "Dental follicle cells and treated dentin matrix scaffold for tissue engineering the tooth root," Biomaterials, vol. 33, no. 5, pp. 1291-1302, 2012.

[31] B. P. Fournier, F. C. Ferre, L. Couty et al., "Multipotent progenitor cells in gingival connective tissue," Tissue Engineering. Part A, vol. 16, no. 9, pp. 2891-2899, 2010.

[32] M. E. Yalvac, M. Ramazanoglu, A. A. Rizvanov et al., "Isolation and characterization of stem cells derived from human third molar tooth germs of young adults: implications in neo-vascularization, osteo-, adipo- and neurogenesis," The Pharmacogenomics Journal, vol. 10, no. 2, pp. 105-113, 2010.

[33] E. Prateeptongkum, C. Klingelhöffer, and C. Morsczeck, "The influence of the donor on dental apical papilla stem cell properties," Tissue \& Cell, vol. 47, no. 4, pp. 382-388, 2015.

[34] G. Chen, J. Chen, B. Yang et al., "Combination of aligned PLGA/gelatin electrospun sheets, native dental pulp extracellular matrix and treated dentin matrix as substrates for tooth root regeneration," Biomaterials, vol. 52, pp. 56-70, 2015.

[35] P. N. Taşlı, S. Aydın, M. E. Yalvaç, and F. Şahin, "Bmp 2 and bmp 7 induce odonto- and osteogenesis of human tooth germ stem cells," Applied Biochemistry and Biotechnology, vol. 172, no. 6, pp. 3016-3025, 2014.

[36] K. M. F. El-Sayed, C. Dörfer, F. Fändrich, F. Gieseler, M. H. Moustafa, and H. Ungefroren, "Adult mesenchymal stem cells explored in the dental field," Advances in Biochemical Engineering/Biotechnology, vol. 130, pp. 89-103, 2013.

[37] K. M. Fawzy el-Sayed, C. Dörfer, F. Fändrich, F. Gieseler, M. H. Moustafa, and H. Ungefroren, "Erratum to: Adult mesenchymal stem cells explored in the dental field," Advances in Biochemical Engineering/Biotechnology, vol. 130, pp. 301-302, 2013. 
[38] R. Kunimatsu, K. Nakajima, T. Awada et al., "Comparative characterization of stem cells from human exfoliated deciduous teeth, dental pulp, and bone marrow-derived mesenchymal stem cells," Biochemical and Biophysical Research Communications, vol. 501, no. 1, pp. 193-198, 2018.

[39] R. Dong, R. Yao, J. du, S. Wang, and Z. Fan, "Depletion of histone demethylase KDM2A enhanced the adipogenic and chondrogenic differentiation potentials of stem cells from apical papilla," Experimental Cell Research, vol. 319, no. 18, pp. 2874-2882, 2013.

[40] H. Salkın, Z. B. Gönen, E. Ergen, D. Bahar, and M. Çetin, "Effects of TGF- $\beta 1$ overexpression on biological characteristics of human dental pulp-derived mesenchymal stromal cells," International Journal of Stem Cells, vol. 12, no. 1, pp. 170-182, 2019.

[41] K. Akiyama, C. Chen, S. Gronthos, and S. Shi, "Lineage differentiation of mesenchymal stem cells from dental pulp, apical papilla, and periodontal ligament," Methods in Molecular Biology, vol. 887, pp. 111-121, 2012.

[42] Y. J. Chen, M. C. Chung, C. C. Jane Yao et al., “The effects of acellular amniotic membrane matrix on osteogenic differentiation and ERK1/2 signaling in human dental apical papilla cells," Biomaterials, vol. 33, no. 2, pp. 455-463, 2012.

[43] S. R. Rao, R. Subbarayan, M. G. Dinesh, G. Arumugam, and S. T. K. Raja, "Differentiation of human gingival mesenchymal stem cells into neuronal lineages in 3D bioconjugated injectable protein hydrogel construct for the management of neuronal disorder," Experimental \& Molecular Medicine, vol. 48, no. 2, article e209, 2016.

[44] J. Ratajczak, A. Bronckaers, Y. Dillen et al., "The neurovascular properties of dental stem cells and their importance in dental tissue engineering," Stem Cells International, vol. 2016, Article ID 9762871, 17 pages, 2016.

[45] P. Pagella, S. Miran, E. Neto, I. Martin, M. Lamghari, and T. A. Mitsiadis, "Human dental pulp stem cells exhibit enhanced properties in comparison to human bone marrow stem cells on neurites outgrowth," The FASEB Journal, vol. 34, no. 4, pp. 5499-5511, 2020.

[46] V. T. Sakai, Z. Zhang, Z. Dong et al., "SHED differentiate into functional odontoblasts and endothelium," Journal of Dental Research, vol. 89, no. 8, pp. 791-796, 2010.

[47] R. d'Aquino, A. Graziano, M. Sampaolesi et al., "Human postnatal dental pulp cells co-differentiate into osteoblasts and endotheliocytes: a pivotal synergy leading to adult bone tissue formation," Cell Death and Differentiation, vol. 14, no. 6, pp. 1162-1171, 2007.

[48] E. Wolmarans, J. Mellet, M. A. Ambele, C. Durandt, and M. S. Pepper, "Heterogeneity of cell therapy products," South African Medical Journal, vol. 109, no. 8b, pp. 2428, 2019.

[49] M. Dominici, K. le Blanc, I. Mueller et al., "Minimal criteria for defining multipotent mesenchymal stromal cells. The International Society for Cellular Therapy position statement," Cytotherapy, vol. 8, no. 4, pp. 315-317, 2006.

[50] F. I. Young, V. Telezhkin, S. J. Youde et al., "Clonal heterogeneity in the neuronal and glial differentiation of dental pulp stem/progenitor cells," Stem Cells International, vol. 2016, Article ID 1290561, 10 pages, 2016.

[51] A. Musiał-Wysocka, M. Kot, and M. Majka, "The pros and cons of mesenchymal stem cell-based therapies," Cell Transplantation, vol. 28, no. 7, pp. 801-812, 2019.
[52] D. Arendt, J. M. Musser, C. V. H. Baker et al., "The origin and evolution of cell types," Nature Reviews. Genetics, vol. 17, no. 12, pp. 744-757, 2016.

[53] Y. Isobe, N. Koyama, K. Nakao et al., "Comparison of human mesenchymal stem cells derived from bone marrow, synovial fluid, adult dental pulp, and exfoliated deciduous tooth pulp," International Journal of Oral and Maxillofacial Surgery, vol. 45, no. 1, pp. 124-131, 2016.

[54] R. Karamzadeh, M. Baghaban Eslaminejad, and A. SharifiZarchi, "Comparative $<i>$ In Vitro $</ i>$ evaluation of human dental pulp and follicle stem cell commitment," Cell Journal, vol. 18, no. 4, pp. 609-618, 2017.

[55] R. J. Waddington, S. J. Youde, C. P. Lee, and A. J. Sloan, "Isolation of distinct progenitor stem cell populations from dental pulp," Cells, Tissues, Organs, vol. 189, no. 1-4, pp. 268274, 2008.

[56] K. Akiyama, C. Chen, D. D. Wang et al., "MesenchymalStem-Cell-Induced Immunoregulation Involves FASLigand-/FAS- Mediated T Cell Apoptosis," Cell Stem Cell, vol. 10, no. 5, pp. 544-555, 2012.

[57] X. Xu, C. Chen, K. Akiyama et al., "Gingivae contain neuralcrest- and mesoderm-derived mesenchymal stem cells," Journal of Dental Research, vol. 92, no. 9, pp. 825-832, 2013.

[58] Q. Zhang, P. D. Nguyen, S. Shi et al., "Neural crest stem-like cells non-genetically induced from human gingiva-derived mesenchymal stem cells promote facial nerve regeneration in rats," Molecular Neurobiology, vol. 55, no. 8, pp. 69656983, 2018.

[59] C. X. Li, N. P. Talele, S. Boo et al., "MicroRNA-21 preserves the fibrotic mechanical memory of mesenchymal stem cells," Nature Materials, vol. 16, no. 3, pp. 379-389, 2017.

[60] C. Yang, M. W. Tibbitt, L. Basta, and K. S. Anseth, "Mechanical memory and dosing influence stem cell fate," Nature Materials, vol. 13, no. 6, pp. 645-652, 2014.

[61] D. T. Scadden, "The stem-cell niche as an entity of action," Nature, vol. 441, no. 7097, pp. 1075-1079, 2006.

[62] N. F. Lizier, A. Kerkis, C. M. Gomes et al., "Scaling-up of dental pulp stem cells isolated from multiple niches," PLoS One, vol. 7, no. 6, article e39885, 2012.

[63] N. Kaukua, M. K. Shahidi, C. Konstantinidou et al., "Glial origin of mesenchymal stem cells in a tooth model system," Nature, vol. 513, no. 7519, pp. 551-554, 2014.

[64] D. Menicanin, P. M. Bartold, A. C. W. Zannettino, and S. Gronthos, "Identification of a common gene expression signature associated with immature clonal mesenchymal cell populations derived from bone marrow and dental tissues," Stem Cells and Development, vol. 19, no. 10, pp. 1501-1510, 2010.

[65] I. Kerkis, A. Kerkis, D. Dozortsev et al., "Isolation and characterization of a population of immature dental pulp stem cells expressing OCT-4 and other embryonic stem cell markers," Cells, Tissues, Organs, vol. 184, no. 3-4, pp. 105-116, 2006.

[66] D. Ma, Z. Ma, X. Zhang et al., "Effect of Age and Extrinsic Microenvironment on the Proliferation and Osteogenic Differentiation of Rat Dental Pulp Stem Cells_In Vitro_," Journal of Endodontia, vol. 35, no. 11, pp. 1546-1553, 2009.

[67] E. Bressan, L. Ferroni, C. Gardin et al., "Donor age-related biological properties of human dental pulp stem cells change in nanostructured scaffolds," PLoS One, vol. 7, no. 11, article e49146, 2012. 
[68] X. Feng, J. Xing, G. Feng et al., “Age-dependent impaired neurogenic differentiation capacity of dental stem cell is associated with Wnt/ $\beta$-catenin signaling," Cellular and Molecular Neurobiology, vol. 33, no. 8, pp. 1023-1031, 2013.

[69] X. Feng, J. Xing, G. Feng et al., "p16 $6^{\text {INK4A }}$ mediates agerelated changes in mesenchymal stem cells derived from human dental pulp through the DNA damage and stress response," Mechanisms of Ageing and Development, vol. 141-142, pp. 46-55, 2014.

[70] D. G. Phinney, G. Kopen, W. Righter, S. Webster, N. Tremain, and D. J. Prockop, "Donor variation in the growth properties and osteogenic potential of human marrow stromal cells," Journal of Cellular Biochemistry, vol. 75, no. 3, pp. 424-436, 1999.

[71] B. J. Sworder, S. Yoshizawa, P. J. Mishra et al., "Molecular profile of clonal strains of human skeletal stem/progenitor cells with different potencies," Stem Cell Research, vol. 14, no. 3, pp. 297-306, 2015.

[72] S. Gronthos, "Molecular and cellular characterisation of highly purified stromal stem cells derived from human bone marrow," Journal of Cell Science, vol. 116, no. 9, pp. 18271835, 2003.

[73] G. T.-J. Huang, W. Sonoyama, J. Chen, and S. H. Park, "In vitro characterization of human dental pulp cells: various isolation methods and culturing environments," Cell and Tissue Research, vol. 324, no. 2, pp. 225-236, 2006.

[74] G. T.-J. Huang, K. Shagramanova, and S. W. Chan, "Formation of odontoblast-like cells from cultured human dental pulp cells on dentin in vitro," Journal of Endodontics, vol. 32, no. 11, pp. 1066-1073, 2006.

[75] C. M. McLeod and R. L. Mauck, "On the origin and impact of mesenchymal stem cell heterogeneity: new insights and emerging tools for single cell analysis," European Cells and Materials, vol. 34, pp. 217-231, 2017.

[76] A. Alraies, N. Y. A. Alaidaroos, R. J. Waddington, R. Moseley, and A. J. Sloan, "Variation in human dental pulp stem cell ageing profiles reflect contrasting proliferative and regenerative capabilities," BMC Cell Biology, vol. 18, no. 1, 2017.

[77] G. Gopinathan, A. Kolokythas, X. Luan, and T. G. H. Diekwisch, "Epigenetic marks define the lineage and differentiation potential of two distinct neural crest-derived intermediate odontogenic progenitor populations," Stem Cells and Development, vol. 22, no. 12, pp. 1763-1778, 2013.

[78] S. Diao, X. Lin, L. Wang et al., "Analysis of gene expression profiles between apical papilla tissues, stem cells from apical papilla and cell sheet to identify the key modulators in MSCs niche," Cell Proliferation, vol. 50, no. 3, p. e12337, 2017.

[79] Y. Cao, D. S. Xia, S. R. Qi et al., "Epiregulin can promote proliferation of stem cells from the dental apical papilla via MEK/Erk and JNK signalling pathways," Cell Proliferation, vol. 46, no. 4, pp. 447-456, 2013.

[80] P. J. Simmons and B. Torok-Storb, "Identification of stromal cell precursors in human bone marrow by a novel monoclonal antibody, STRO-1," Blood, vol. 78, no. 1, pp. 55-62, 1991.

[81] A. Bakopoulou, G. Leyhausen, J. Volk, P. Koidis, and W. Geurtsen, "Comparative characterization of STRO$1^{\text {neg }} / \mathrm{CD} 146^{\text {pos }}$ and STRO- ${ }^{\text {pos }} / \mathrm{CD} 146^{\text {pos }}$ apical papilla stem cells enriched with flow cytometry," Archives of Oral Biology, vol. 58, no. 10, pp. 1556-1568, 2013.
[82] J. Yu, H. He, C. Tang et al., "Differentiation potential of STRO-1+ dental pulp stem cells changes during cell passaging," BMC Cell Biology, vol. 11, no. 1, 2010.

[83] X. Yang, X. F. Walboomers, J. J. J. P. van den Beucken, Z. Bian, M. Fan, and J. A. Jansen, "Hard tissue formation of STRO-1-selected rat dental pulp stem cells in vivo," Tissue Engineering Part A, vol. 15, no. 2, pp. 367-375, 2009.

[84] M. Ginsburg, M. H. Snow, and A. McLaren, "Primordial germ cells in the mouse embryo during gastrulation," Development, vol. 110, no. 2, pp. 521-528, 1990.

[85] D. Langer, Y. Ikehara, H. Takebayashi, R. Hawkes, and H. Zimmermann, "The ectonucleotidases alkaline phosphatase and nucleoside triphosphate diphosphohydrolase 2 are associated with subsets of progenitor cell populations in the mouse embryonic, postnatal and adult neurogenic zones," Neuroscience, vol. 150, no. 4, pp. 863-879, 2007.

[86] A. Dellavalle, M. Sampaolesi, R. Tonlorenzi et al., "Pericytes of human skeletal muscle are myogenic precursors distinct from satellite cells," Nature Cell Biology, vol. 9, no. 3, pp. 255-267, 2007.

[87] V. L. Battula, S. Treml, P. M. Bareiss et al., "Isolation of functionally distinct mesenchymal stem cell subsets using antibodies against CD56, CD271, and mesenchymal stem cell antigen-1," Haematologica, vol. 94, no. 2, pp. 173-184, 2009.

[88] E. Inada, I. Saitoh, N. Kubota et al., "Alkaline phosphatase and OCT-3/4 as useful markers for predicting susceptibility of human deciduous teeth-derived dental pulp cells to reprogramming factor-induced iPS cells," Journal of Investigative and Clinical Dentistry, vol. 8, no. 4, 2017.

[89] Z. Y. Philippe, "Differential properties of human ALP(+) periodontal ligament stem cells vs their ALP(-) counterparts," Journal of Stem Cell Research \& Therapy, vol. 5, no. 7, 2015.

[90] J.-C. Park, Y. Herr, H.-J. Kim, R. M. Gronostajski, and M.I. Cho, "Nfic gene disruption inhibits differentiation of odontoblasts responsible for root formation and results in formation of short and abnormal roots in mice," Journal of Periodontology, vol. 78, no. 9, pp. 1795-1802, 2007.

[91] J. Zhang, Z. Wang, Y. Jiang et al., "Nuclear factor I-C promotes proliferation and differentiation of apical papilladerived human stem cells in vitro," Experimental Cell Research, vol. 332, no. 2, pp. 259-266, 2015.

[92] S. Gao, Y. M. Zhao, and L. H. Ge, "Nuclear factor I-C expression pattern in developing teeth and its important role in odontogenic differentiation of human molar stem cells from the apical papilla," European Journal of Oral Sciences, vol. 122, no. 6, pp. 382-390, 2014.

[93] F. Zhang, M. Liang, C. Zhao, Y. Fu, and S. Yu, "NFIC promotes the vitality and osteogenic differentiation of rat dental follicle cells," Journal of Molecular Histology, vol. 50, no. 5, pp. 471-482, 2019.

[94] G. T.-J. Huang, T. Yamaza, L. D. Shea et al., "Stem/progenitor cell-mediated de novo regeneration of dental pulp with newly deposited continuous layer of dentin in an in vivo model," Tissue Engineering Part A, vol. 16, no. 2, pp. 605-615, 2010.

[95] Z. Wang and X. Yan, "CD146, a multi-functional molecule beyond adhesion," Cancer Letters, vol. 330, no. 2, pp. 150162, 2013.

[96] S. Stopp, M. Bornhauser, F. Ugarte et al., "Expression of the melanoma cell adhesion molecule in human mesenchymal stromal cells regulates proliferation, differentiation, and 
maintenance of hematopoietic stem and progenitor cells," Haematologica, vol. 98, no. 4, pp. 505-513, 2013.

[97] L. Harkness, W. Zaher, N. Ditzel, A. Isa, and M. Kassem, "CD146/MCAM defines functionality of human bone marrow stromal stem cell populations," Stem Cell Research \& Therapy, vol. 7, no. 1, 2016.

[98] M. Matsui, T. Kobayashi, and T. W. Tsutsui, “CD146 positive human dental pulp stem cells promote regeneration of dentin/pulp-like structures," Human Cell, vol. 31, no. 2, pp. 127-138, 2018.

[99] G. D. M. Collett and A. E. Canfield, "Angiogenesis and pericytes in the initiation of ectopic calcification," Circulation Research, vol. 96, no. 9, pp. 930-938, 2005.

[100] L. Dubanet, H. Bentayeb, B. Petit et al., “Anti-apoptotic role and clinical relevance of neurotrophins in diffuse large Bcell lymphomas," British Journal of Cancer, vol. 113, no. 6, pp. 934-944, 2015.

[101] K. M. Young, T. D. Merson, A. Sotthibundhu, E. J. Coulson, and P. F. Bartlett, "p75 neurotrophin receptor expression defines a population of BDNF-responsive neurogenic precursor cells," Journal of Neuroscience, vol. 27, no. 19, pp. 51465155, 2007.

[102] V. S. Catts, N. Al-Menhali, T. H. J. Burne, M. J. Colditz, and E. J. Coulson, “The p75 neurotrophin receptor regulates hippocampal neurogenesis and related behaviours," European Journal of Neuroscience, vol. 28, no. 5, pp. 883-892, 2008.

[103] W. Pan, K. L. Kremer, X. Kaidonis et al., "Characterization of p75 neurotrophin receptor expression in human dental pulp stem cells," International Journal of Developmental Neuroscience, vol. 53, no. 1, pp. 90-98, 2016.

[104] L. E. Sidney, M. J. Branch, S. E. Dunphy, H. S. Dua, and A. Hopkinson, "Concise review: evidence for CD34 as a common marker for diverse progenitors," Stem Cells, vol. 32, no. 6, pp. 1380-1389, 2014.

[105] P. J. Simmons and B. Torok-Storb, "CD34 expression by stromal precursors in normal human adult bone marrow," Blood, vol. 78, no. 11, pp. 2848-2853, 1991.

[106] A. Pisciotta, G. Carnevale, S. Meloni et al., "Human dental pulp stem cells (hDPSCs): isolation, enrichment and comparative differentiation of two sub-populations," BMC Developmental Biology, vol. 15, no. 1, 2015.

[107] G. Carnevale, A. Pisciotta, M. Riccio et al., "Human dental pulp stem cells expressing STRO-1, c-kit and CD34 markers in peripheral nerve regeneration," Journal of Tissue Engineering and Regenerative Medicine, vol. 12, no. 2, pp. e774-e785, 2018.

[108] H. Wang and Y. Cao, "WIF1 enhanced dentinogenic differentiation in stem cells from apical papilla," BMC Oral Health, vol. 19, no. 1, p. 25, 2019.

[109] K. Pomduk, P. Kheolamai, Y. U-Pratya, M. Wattanapanitch, N. Klincumhom, and S. Issaragrisil, "Enhanced human mesenchymal stem cell survival under oxidative stress by overexpression of secreted frizzled-related protein 2 gene," Annals of Hematology, vol. 94, no. 2, pp. 319-327, 2015.

[110] X. Lin, R. Dong, S. Diao et al., "SFRP2 enhanced the adipogenic and neuronal differentiation potentials of stem cells from apical papilla," Cell Biology International, vol. 41, no. 5, pp. 534-543, 2017.

[111] A. Ehrlund, N. Mejhert, S. Lorente-Cebrián et al., "Characterization of the Wnt inhibitors secreted frizzled-related proteins (SFRPs) in human adipose tissue," The Journal of
Clinical Endocrinology \& Metabolism, vol. 98, no. 3, pp. E503-E508, 2013.

[112] G. Yu, J. Wang, X. Lin et al., "Demethylation of SFRP2 by histone demethylase KDM2A regulated osteo-/dentinogenic differentiation of stem cells of the apical papilla," Cell Proliferation, vol. 49, no. 3, pp. 330-340, 2016.

[113] G. B. Downes and N. Gautam, “The G protein subunit gene families," Genomics, vol. 62, no. 3, pp. 544-552, 1999.

[114] G. Chen, X. Li, G. He et al., "Low expression of GNAI3 predicts poor prognosis in patients with HCC," International Journal Clininical and Experimental Medicine, vol. 8, no. 11, pp. 21482-21486, 2015.

[115] I.-Y. Hwang, C. Park, T. Luong, K. A. Harrison, L. Birnbaumer, and J. H. Kehrl, "The loss of Gnai2 and Gnai3 in B cells eliminates B lymphocyte compartments and leads to a hyper-IgM like syndrome," PLoS One, vol. 8, no. 8, article e72596, 2013.

[116] S. A. K. Rasheed, C. R. Teo, E. J. Beillard, P. M. Voorhoeve, and P. J. Casey, "MicroRNA-182 and MicroRNA-200a Control G-protein Subunit $\alpha$-13 (GNA13) Expression and Cell Invasion Synergistically in Prostate Cancer Cells," Journal of Biological Chemistry, vol. 288, no. 11, pp. 7986-7995, 2013.

[117] Y. Zhang, L. Yuan, L. Meng et al., "Guanine and nucleotide binding protein 3 promotes odonto/osteogenic differentiation of apical papilla stem cells via JNK and ERK signaling pathways," International Journal of Molecular Medicine, vol. 43, no. 1, pp. 382-392, 2018.

[118] Y. Wang, X. Chen, W. Cao, and Y. Shi, "Plasticity of mesenchymal stem cells in immunomodulation: pathological and therapeutic implications," Nature Immunology, vol. 15, no. 11, pp. 1009-1016, 2014.

[119] H. Yang, R. M. Aprecio, X. Zhou et al., "Therapeutic effect of TSG-6 engineered iPSC-derived MSCs on experimental periodontitis in rats: a pilot study," PLoS One, vol. 9, no. 6, article e100285, 2014.

[120] R. Yang, T. Yu, and Y. Zhou, "Interplay between craniofacial stem cells and immune stimulus," Stem Cell Research \& Therapy, vol. 8, no. 1, 2017.

[121] O. Andrukhov, C. Behm, A. Blufstein, and X. Rausch-Fan, "Immunomodulatory properties of dental tissue-derived mesenchymal stem cells: implication in disease and tissue regeneration," World Journal of Stem Cells, vol. 11, no. 9, pp. 604-617, 2019.

[122] A. Nasef, Y. Z. Zhang, C. Mazurier et al., "Selected Stro-1enriched bone marrow stromal cells display a major suppressive effect on lymphocyte proliferation," International Journal of Laboratory Hematology, vol. 31, no. 1, pp. 9-19, 2009.

[123] Y. Zhang, D. Zhao, C. Tian et al., "Stro-1-positive human mesenchymal stem cells prolong skin graft survival in mice," Transplantation Proceedings, vol. 45, no. 2, pp. 726-729, 2013.

[124] C. Shin, M. Kim, J.-A. Han et al., "Human periodontal ligament stem cells suppress $\mathrm{T}$-cell proliferation via downregulation of non-classical major histocompatibility complex-like glycoprotein CD1b on dendritic cells," Journal of Periodontal Research, vol. 52, no. 1, pp. 135-146, 2017.

[125] K. H. Kwack, J. M. Lee, S. H. Park, and H. W. Lee, "Human dental pulp stem cells suppress alloantigen-induced immunity by stimulating $\mathrm{T}$ cells to release transforming growth factor beta," Journal of Endodontics, vol. 43, no. 1, pp. 100-108, 2017. 
[126] M. Zaim, S. Karaman, G. Cetin, and S. Isik, "Donor age and long-term culture affect differentiation and proliferation of human bone marrow mesenchymal stem cells," Annals of Hematology, vol. 91, no. 8, pp. 1175-1186, 2012.

[127] C. Morsczeck, J. Gresser, and T. Ettl, “The induction of cellular senescence in dental follicle cells inhibits the osteogenic differentiation," Molecular and Cellular Biochemistry, vol. 417, no. 1-2, pp. 1-6, 2016.

[128] X. Li, B. Zhang, H. Wang et al., "The effect of aging on the biological and immunological characteristics of periodontal ligament stem cells," Stem Cell Research \& Therapy, vol. 11, no. 1, p. 326, 2020.

[129] F. Rodier and J. Campisi, "Four faces of cellular senescence," Journal of Cell Biology, vol. 192, no. 4, pp. 547-556, 2011.

[130] H. Horibe, M. Murakami, K. Iohara et al., "Isolation of a stable subpopulation of mobilized dental pulp stem cells (MDPSCs) with high proliferation, migration, and regeneration potential is independent of age," PLoS One, vol. 9, no. 5, article e98553, 2014.

[131] M. Nakashima and K. Iohara, "Mobilized dental pulp stem cells for pulp regeneration: initiation of clinical trial," Journal of Endodontics, vol. 40, no. 4, pp. S26-S32, 2014.

[132] L. Zhang, "Control of growth and beyond: a special issue on Hippo signaling," Acta Biochimica et Biophysica Sinica, vol. 47 , no. 1, p. 1, 2015.

[133] A. M. Tremblay and F. D. Camargo, "Hippo signaling in mammalian stem cells," Seminars in Cell \& Developmental Biology, vol. 23, no. 7, pp. 818-826, 2012.

[134] K. Yoshikawa, K. Noguchi, Y. Nakano et al., "The Hippo pathway transcriptional co-activator, YAP, confers resistance to cisplatin in human oral squamous cell carcinoma," International Journal of Oncology, vol. 46, no. 6, pp. 2364-2370, 2015.

[135] L. Jia, W. Gu, Y. Zhang, B. Jiang, X. Qiao, and Y. Wen, “Activated Yes-associated protein accelerates cell cycle, inhibits apoptosis, and delays senescence in human periodontal ligament stem cells," International Journal of Medical Sciences, vol. 15, no. 11, pp. 1241-1250, 2018.

[136] Y. Wen, Y. Ji, Y. Zhang et al., "Knockdown of Yes-associated protein induces the apoptosis while inhibits the proliferation of human periodontal ligament stem cells through crosstalk between Erk and Bcl-2 signaling pathways," International Journal of Medical Sciences, vol. 14, no. 12, pp. 1231-1240, 2017.

[137] S.-Y. Hyun, J.-H. Lee, K.-J. Kang, and Y.-J. Jang, "Effect of FGF-2, TGF- $\beta$-1, and BMPs on teno/ligamentogenesis and osteo/cementogenesis of human periodontal ligament stem cells," Molecules and Cells, vol. 40, no. 8, pp. 550-557, 2017.

[138] C. Fan, Q. Ji, C. Zhang, S. Xu, H. Sun, and Z. Li, “TGF- $\beta$ induces periodontal ligament stem cell senescence through increase of ROS production," Molecular Medicine Reports, vol. 20, no. 4, pp. 3123-3130, 2019.

[139] C. D. Allis and T. Jenuwein, "The molecular hallmarks of epigenetic control," Nature Reviews Genetics, vol. 17, no. 8, pp. 487-500, 2016.

[140] L. Fagnocchi, S. Mazzoleni, and A. Zippo, "Integration of signaling pathways with the epigenetic machinery in the maintenance of stem cells," Stem Cells International, vol. 2016, Article ID 8652748, 13 pages, 2016.

[141] K. Nishino and A. Umezawa, "DNA methylation dynamics in human induced pluripotent stem cells," Human Cell, vol. 29, no. 3, pp. 97-100, 2016.
[142] K. Dunaway, S. Goorha, L. Matelski et al., "Dental pulp stem cells model early life and imprinted DNA methylation patterns," Stem Cells, vol. 35, no. 4, pp. 981-988, 2017.

[143] A. Bird, "DNA methylation patterns and epigenetic memory," Genes \& Development, vol. 16, no. 1, pp. 6-21, 2002.

[144] X. Yan, S. Ehnert, M. Culmes et al., "5-Azacytidine improves the osteogenic differentiation potential of aged human adipose-derived mesenchymal stem cells by DNA demethylation," PLoS One, vol. 9, no. 3, article e90846, 2014.

[145] Y. Rui, L. Xu, R. Chen et al., "Epigenetic memory gained by priming with osteogenic induction medium improves osteogenesis and other properties of mesenchymal stem cells," Scientific Reports, vol. 5, no. 1, 2015.

[146] X. Yang, F. Lay, H. Han, and P. A. Jones, "Targeting DNA methylation for epigenetic therapy," Trends in Pharmacological Sciences, vol. 31, no. 11, pp. 536-546, 2010.

[147] Z. Liu, T. Chen, W. Sun et al., "DNA demethylation rescues the impaired osteogenic differentiation ability of human periodontal ligament stem cells in high glucose," Scientific Reports, vol. 6, no. 1, 2016.

[148] D. Zhang, Q. Li, L. Rao, B. Yi, and Q. Xu, "Effect of 5-aza-2' -deoxycytidine on odontogenic differentiation of human dental pulp cells," Journal of Endodontics, vol. 41, no. 5, pp. 640-645, 2015.

[149] R. Nakatsuka, T. Nozaki, Y. Uemura et al., "5-Aza-2' -deoxycytidine treatment induces skeletal myogenic differentiation of mouse dental pulp stem cells," Archives of Oral Biology, vol. 55, no. 5, pp. 350-357, 2010.

[150] S. Ito, A. C. D’Alessio, O. V. Taranova, K. Hong, L. C. Sowers, and Y. Zhang, "Role of Tet proteins in $5 \mathrm{mC}$ to $5 \mathrm{hmC}$ conversion, ES-cell self-renewal and inner cell mass specification," Nature, vol. 466, no. 7310, pp. 1129-1133, 2010.

[151] R. Kim, K. L. Sheaffer, I. Choi, K.-J. Won, and K. H. Kaestner, "Epigenetic regulation of intestinal stem cells by Tet1mediated DNA hydroxymethylation," Genes \& Development, vol. 30, no. 21, pp. 2433-2442, 2016.

[152] X. Wu, G. Li, and R. Xie, "Decoding the role of TET family dioxygenases in lineage specification," Epigenetics \& Chromatin, vol. 11, no. 1, p. 58, 2018.

[153] T. Yu, D. Liu, T. Zhang, Y. Zhou, S. Shi, and R. Yang, "Inhibition of Tet1- and Tet2-mediated DNA demethylation promotes immunomodulation of periodontal ligament stem cells," Cell Death \& Disease, vol. 10, no. 10, p. 780, 2019.

[154] V. Shukla, T. Vaissière, and Z. Herceg, "Histone acetylation and chromatin signature in stem cell identity and cancer," Mutation Research/Fundamental and Molecular Mechanisms of Mutagenesisutation Research/Fundamental and Molecular Mechanisms of Mutagenesis, vol. 637, no. 1-2, pp. 1-15, 2008.

[155] D. E. Handy, R. Castro, and J. Loscalzo, "Epigenetic modifications: basic mechanisms and role in cardiovascular disease," Circulation, vol. 123, no. 19, pp. 2145-2156, 2011.

[156] P. D. Gregory, K. Wagner, and W. Hörz, "Histone acetylation and chromatin remodeling," Experimental Cell Research, vol. 265, no. 2, pp. 195-202, 2001.

[157] E. Seto and M. Yoshida, "Erasers of histone acetylation: the histone deacetylase enzymes," Cold Spring Harbor Perspectives in Biology, vol. 6, no. 4, p. a018713, 2014.

[158] O. Destaing, "A novel Rho-mDia2-HDAC6 pathway controls podosome patterning through microtubule acetylation in osteoclasts," Journal of Cell Science, vol. 118, no. 13, pp. 2901-2911, 2005. 
[159] J. Sun, Z. Dong, Y. Zhang et al., "Osthole improves function of periodontitis periodontal ligament stem cells via epigenetic modification in cell sheets engineering," Scientific Reports, vol. 7, no. 1, p. 5254, 2017.

[160] N. C.-N. Huynh, V. Everts, P. Pavasant, and R. S. Ampornaramveth, "Inhibition of histone deacetylases enhances the osteogenic differentiation of human periodontal ligament cells," Journal of Cellular Biochemistry, vol. 117, no. 6, pp. 1384-1395, 2016.

[161] Z. Liu, T. Chen, Q. Han et al., "HDAC inhibitor LMK-235 promotes the odontoblast differentiation of dental pulp cells," Molecular Medicine Reports, vol. 17, no. 1, pp. 1445-1452, 2017.

[162] E.-C. Lee, Y.-M. Kim, H.-M. Lim, G.-E. Ki, and Y.-K. Seo, “The histone deacetylase inhibitor (MS-275) promotes differentiation of human dental pulp stem cells into odontoblast-like cells independent of the MAPK signaling system," International Journal of Molecular Sciences, vol. 21, no. 16, p. 5771, 2020.

[163] B. Li, J. Sun, Z. Dong et al., "GCN5 modulates osteogenic differentiation of periodontal ligament stem cells through DKK1 acetylation in inflammatory microenvironment," Scientific Reports, vol. 6, no. 1, 2016.

[164] F. Paino, M. la Noce, V. Tirino et al., "Histone deacetylase inhibition with valproic acid downregulates osteocalcin gene expression in human dental pulp stem cells and osteoblasts: evidence for HDAC2 involvement," Stem Cells, vol. 32, no. 1, pp. 279-289, 2014.

[165] M. la Noce, L. Mele, L. Laino et al., "Cytoplasmic interactions between the glucocorticoid receptor and HDAC2 regulate osteocalcin expression in VPA-treated MSCs," Cells, vol. 8, no. 3, p. 217, 2019.

[166] M. Haberland, R. L. Montgomery, and E. N. Olson, "The many roles of histone deacetylases in development and physiology: implications for disease and therapy," Nature Reviews. Genetics, vol. 10, no. 1, pp. 32-42, 2009.

[167] Q. Li, Y. Ma, Y. Zhu, T. Zhang, and Y. Zhou, "Declined expression of histone deacetylase 6 contributes to periodontal ligament stem cell aging," Journal of Periodontology, vol. 88, no. 1, pp. e12-e23, 2017.

[168] M. Esteller, "Non-coding RNAs in human disease," Nature Reviews. Genetics, vol. 12, no. 12, pp. 861-874, 2011.

[169] S. Ergun and S. Oztuzcu, "Oncocers: ceRNA-mediated crosstalk by sponging miRNAs in oncogenic pathways," Tumour Biology, vol. 36, no. 5, pp. 3129-3136, 2015.

[170] Z. Liu, S. Xu, J. Dao, Z. Gan, and X. Zeng, "Differential expression of $\operatorname{lncRNA} / \mathrm{miRNA} / \mathrm{mRNA}$ and their related functional networks during the osteogenic/odontogenic differentiation of dental pulp stem cells," Journal of Cellular Physiology, vol. 235, no. 4, pp. 3350-3361, 2020.

[171] B. John, A. J. Enright, A. Aravin, T. Tuschl, C. Sander, and D. S. Marks, "Human microRNA targets," PLoS Biology, vol. 2, no. 11, article e363, 2004.

[172] L. P. Lim, N. C. Lau, P. Garrett-Engele et al., "Microarray analysis shows that some microRNAs downregulate large numbers of target mRNAs," Nature, vol. 433, no. 7027, pp. 769-773, 2005.

[173] K. N. Ivey and D. Srivastava, "MicroRNAs as regulators of differentiation and cell fate decisions," Cell Stem Cell, vol. 7, no. 1, pp. 36-41, 2010.

[174] Y. Hao, Y. Ge, J. Li, Y. Hu, B. Wu, and F. Fang, "Identification of microRNAs by microarray analysis and prediction of tar- get genes involved in osteogenic differentiation of human periodontal ligament stem cells," Journal of Periodontology, vol. 88, no. 10, pp. 1105-1113, 2017.

[175] J. T. Y. Kung, D. Colognori, and J. T. Lee, "Long noncoding RNAs: past, present, and future," Genetics, vol. 193, no. 3, pp. 651-669, 2013.

[176] A. Fatica and I. Bozzoni, "Long non-coding RNAs: new players in cell differentiation and development," Nature Reviews. Genetics, vol. 15, no. 1, pp. 7-21, 2014.

[177] K. Ren, Y. Li, H. Lu et al., "Long noncoding RNA HOTAIR controls cell cycle by functioning as a competing endogenous RNA in esophageal squamous cell carcinoma," Translational Oncology, vol. 9, no. 6, pp. 489-497, 2016.

[178] C. Liao, Y. Zhou, M. Li, Y. Xia, and W. Peng, "LINC00968 promotes osteogenic differentiation in vitro and bone formation in vivo via regulation of miR-3658/RUNX2," Differentiation, vol. 116, pp. 1-8, 2020.

[179] L. Jia, Y. Zhang, Y. Ji et al., "Comparative analysis of lncRNA and mRNA expression profiles between periodontal ligament stem cells and gingival mesenchymal stem cells," Gene, vol. 699, pp. 155-164, 2019.

[180] M. Guo, J. Qiu, F. Shen et al., "Comprehensive analysis of circular RNA profiles in skeletal muscles of aging mice and after aerobic exercise intervention," Aging, vol. 12, no. 6, pp. 50715090, 2020.

[181] W. R. Jeck, J. A. Sorrentino, K. Wang et al., "Circular RNAs are abundant, conserved, and associated with ALU repeats," $R N A$, vol. 19, no. 2, pp. 141-157, 2013.

[182] S. Qu, X. Yang, X. Li et al., "Circular RNA: a new star of noncoding RNAs," Cancer Letters, vol. 365, no. 2, pp. 141-148, 2015.

[183] M. Chen, Y. Yang, J. Zeng, Z. Deng, and B. Wu, “circRNA expression profile in dental pulp stem cells during odontogenic differentiation," Stem Cells International, vol. 2020, Article ID 5405931, 19 pages, 2020.

[184] X. Li, Y. Zheng, Y. Zheng et al., "Circular RNA CDR1as regulates osteoblastic differentiation of periodontal ligament stem cells via the miR-7/GDF5/SMAD and p38 MAPK signaling pathway," Stem Cell Research \& Therapy, vol. 9, no. 1, p. 232, 2018.

[185] F. Wang, X. Chen, Y. Han, S. Xi, and G. Wu, "circRNA $\mathrm{CDR} 1$ as regulated the proliferation of human periodontal ligament stem cells under a lipopolysaccharide-induced inflammatory condition," Mediators of Inflammation, vol. 2019, Article ID 1625381, 9 pages, 2019.

[186] S. Kim, S.-J. Shin, Y. Song, and E. Kim, "In vivo experiments with dental pulp stem cells for pulp-dentin complex regeneration," Mediators of Inflammation, vol. 2015, Article ID 409347, 6 pages, 2015.

[187] B. Sui, C. Chen, X. Kou et al., "Pulp stem cell-mediated functional pulp regeneration," Journal of Dental Research, vol. 98, no. 1, pp. 27-35, 2019.

[188] G. Orsini, P. Pagella, and T. A. Mitsiadis, "Modern trends in dental medicine: an update for internists," The American Journal of Medicine, vol. 131, no. 12, pp. 1425-1430, 2018.

[189] M. Tatullo, B. Codispoti, F. Paduano, M. Nuzzolese, and I. Makeeva, "Strategic tools in regenerative and translational dentistry," International Journal of Molecular Sciences, vol. 20, no. 8, p. 1879, 2019.

[190] P. Stanko, U. Altanerova, J. Jakubechova, V. Repiska, and C. Altaner, "Dental mesenchymal stem/stromal cells and 
their exosomes," Stem Cells International, vol. 2018, Article ID 8973613, 8 pages, 2018.

[191] Y. Yamada, S. Nakamura-Yamada, K. Kusano, and S. Baba, "Clinical potential and current progress of dental pulp stem cells for various systemic diseases in regenerative medicine: a concise review," International Journal of Molecular Sciences, vol. 20, no. 5, p. 1132, 2019.

[192] Y. Yamada, S. Nakamura-Yamada, R. Konoki, and S. Baba, "Promising advances in clinical trials of dental tissuederived cell-based regenerative medicine," Stem Cell Research \& Therapy, vol. 11, no. 1, p. 175, 2020.

[193] K. Xuan, B. Li, H. Guo et al., "Deciduous autologous tooth stem cells regenerate dental pulp after implantation into injured teeth," Science Translational Medicine, vol. 10, no. 455, p. eaaf3227, 2018.

[194] C. Brown, C. McKee, S. Bakshi et al., "Mesenchymal stem cells: cell therapy and regeneration potential," Journal of Tissue Engineering and Regenerative Medicine, vol. 13, no. 9, pp. 1738-1755, 2019.

[195] N. Y. A. Alaidaroos, A. Alraies, R. J. Waddington, A. J. Sloan, and R. Moseley, "Differential SOD2 and GSTZ1 profiles contribute to contrasting dental pulp stem cell susceptibilities to oxidative damage and premature senescence," Stem Cell Research \& Therapy, vol. 12, no. 1, p. 142, 2021.

[196] A. Alraies, R. J. Waddington, A. J. Sloan, and R. Moseley, "Evaluation of dental pulp stem cell heterogeneity and behaviour in 3D type I collagen gels," BioMed Research International, vol. 2020, Article ID 3034727, 12 pages, 2020.

[197] N. M. Mount, S. J. Ward, P. Kefalas, and J. Hyllner, "Cellbased therapy technology classifications and translational challenges," Philosophical Transactions of the Royal Society of London. Series B, Biological Sciences, vol. 370, no. 1680, p. 20150017, 2015.

[198] V. Uribe-Etxebarria, P. García-Gallastegui, M. Pérez-Garrastachu et al., "Wnt-3a induces epigenetic remodeling in human dental pulp stem cells," Cell, vol. 9, no. 3, p. 652, 2020.

[199] F. Diomede, N. Zini, J. Pizzicannella et al., "5-Aza exposure improves reprogramming process through embryoid body formation in human gingival stem cells," Frontiers in Genetics, vol. 9, p. 419, 2018.

[200] R. Alvarez, H.-L. Lee, C. Hong, and C.-Y. Wang, "Single CD271 marker isolates mesenchymal stem cells from human dental pulp," International Journal of Oral Science, vol. 7, no. 4, pp. 205-212, 2015.

[201] H. F. Duncan, A. J. Smith, G. J. P. Fleming, and P. R. Cooper, "Epigenetic modulation of dental pulp stem cells: implications for regenerative endodontics," International Endodontic Journal, vol. 49, no. 5, pp. 431-446, 2016.

[202] L. Wen and F. Tang, "Single-cell sequencing in stem cell biology," Genome Biology, vol. 17, no. 1, 2016.

[203] R. Schäfer, G. Spohn, and P. C. Baer, "Mesenchymal stem/stromal cells in regenerative medicine: can preconditioning strategies improve therapeutic efficacy?," Transfusion Medicine and Hemotherapy, vol. 43, no. 4, pp. 256267, 2016.

[204] L. Zeng, S. Sun, D. Han et al., "Long non-coding RNA H19/SAHH axis epigenetically regulates odontogenic differentiation of human dental pulp stem cells," Cellular Signalling, vol. 52, pp. 65-73, 2018.

[205] M. Rostovskaya, S. Donsante, B. Sacchetti et al., "Clonal analysis delineates transcriptional programs of osteogenic and adipogenic lineages of adult mouse skeletal progenitors," Stem Cell Reports, vol. 11, no. 1, pp. 212-227, 2018.

[206] A. De Becker and I. V. Riet, "Homing and migration of mesenchymal stromal cells: how to improve the efficacy of cell therapy?," World Journal of Stem Cells, vol. 8, no. 3, pp. 7387,2016

[207] A. Wilson, A. Webster, and P. Genever, "Nomenclature and heterogeneity: consequences for the use of mesenchymal stem cells in regenerative medicine," Regenerative Medicine, vol. 14, no. 6, pp. 595-611, 2019.

[208] K. Iohara, K. Imabayashi, R. Ishizaka et al., "Complete pulp regeneration after pulpectomy by transplantation of CD105+ stem cells with stromal cell-derived factor-1," Tissue Engineering. Part A, vol. 17, no. 15-16, pp. 1911-1920, 2011.

[209] M. Nakashima, K. Iohara, M. Murakami et al., "Pulp regeneration by transplantation of dental pulp stem cells in pulpitis: a pilot clinical study," Stem Cell Research \& Therapy, vol. 8, no. 1, p. 61, 2017.

[210] M. Nakashima and K. Iohara, "Recent progress in translation from bench to a pilot clinical study on total pulp regeneration," Journal of Endodontia, vol. 43, no. 9, pp. S82-s86, 2017.

[211] E. Vescarelli, A. Pilloni, F. Dominici et al., "Autophagy activation is required for myofibroblast differentiation during healing of oral mucosa," Journal of Clinical Periodontology, vol. 44, no. 10, pp. 1039-1050, 2017.

[212] R. Schäfer, "Advanced cell therapeutics are changing the clinical landscape: will mesenchymal stromal cells be a part of it?," BMC Medicine, vol. 17, no. 1, p. 53, 2019.

[213] P. Hilkens, P. Gervois, Y. Fanton et al., "Effect of isolation methodology on stem cell properties and multilineage differentiation potential of human dental pulp stem cells," Cell and Tissue Research, vol. 353, no. 1, pp. 65-78, 2013.

[214] L. Fracaro, A. C. Senegaglia, R. H. Herai et al., "The expression profile of dental pulp-derived stromal cells supports their limited capacity to differentiate into adipogenic cells," International Journal of Molecular Sciences, vol. 21, no. 8, p. 2753, 2020.

[215] A.-R. Youssef, R. Emara, M. M. Taher et al., "Effects of mineral trioxide aggregate, calcium hydroxide, biodentine and Emdogain on osteogenesis, Odontogenesis, angiogenesis and cell viability of dental pulp stem cells," BMC Oral Health, vol. 19, no. 1, p. 133, 2019.

[216] H. Seonwoo, K.-J. Jang, D. Lee et al., "Neurogenic differentiation of human dental pulp stem cells on graphenepolycaprolactone hybrid nanofibers," Nanomaterials, vol. 8, no. 7, p. 554, 2018.

[217] M. Oh, Z. Zhang, A. Mantesso, A. E. Oklejas, and J. E. Nör, "Endothelial-initiated crosstalk regulates dental pulp stem cell self-renewal," Journal of Dental Research, vol. 99, no. 9, pp. 1102-1111, 2020.

[218] V. Rosa, N. Dubey, I. Islam, K.-S. Min, and J. E. Nör, "Pluripotency of stem cells from human exfoliated deciduous teeth for tissue engineering," Stem Cells International, vol. 2016, Article ID 5957806, 6 pages, 2016.

[219] A. Jarmalavičiūte, V. Tunaitis, E. Strainienè et al., "A new experimental model for neuronal and glial differentiation using stem cells derived from human exfoliated deciduous teeth," Journal of Molecular Neuroscience, vol. 51, no. 2, pp. 307-317, 2013.

[220] N. Zhang, B. Chen, W. Wang et al., "Isolation, characterization and multi-lineage differentiation of stem cells from 
human exfoliated deciduous teeth," Molecular Medicine Reports, vol. 14, no. 1, pp. 95-102, 2016.

[221] W. Zhang, X. Zhang, J. Ling, X. Wei, and Y. Jian, “Osteo/odontogenic differentiation of BMP2 and VEGF gene-cotransfected human stem cells from apical papilla," Molecular Medicine Reports, vol. 13, no. 5, pp. 3747-3754, 2016.

[222] S. Yu, Y. Zhao, T. J. Fang, and L. Ge, "Effect of the soluble factors released by dental apical papilla-derived stem cells on the osteo/odontogenic, angiogenic, and neurogenic differentiation of dental pulp cells," Stem Cells and Development, vol. 29, no. 12, pp. 795-805, 2020.

[223] B.-M. Seo, M. Miura, S. Gronthos et al., "Investigation of multipotent postnatal stem cells from human periodontal ligament," The Lancet, vol. 364, no. 9429, pp. 149-155, 2004.

[224] S. Ansari, I. M. Diniz, C. Chen et al., "Human periodontal ligament- and gingiva-derived mesenchymal stem cells promote nerve regeneration when encapsulated in alginate/hyaluronic acid 3D scaffold," Advanced Healthcare Materials, vol. 6, no. 24, 2017.

[225] S. Ansari, I. M. Diniz, C. Chen et al., "Alginate/hyaluronic acid hydrogel delivery system characteristics regulate the differentiation of periodontal ligament stem cells toward chondrogenic lineage," Journal of Materials Science. Materials in Medicine, vol. 28, no. 10, 2017.

[226] C. Morsczeck, F. Völlner, M. Saugspier et al., "Comparison of human dental follicle cells (DFCs) and stem cells from human exfoliated deciduous teeth (SHED) after neural differentiation in vitro," Clinical Oral Investigations, vol. 14, no. 4, pp. 433-440, 2010.

[227] X. Li, C. Yang, L. Li et al., "A therapeutic strategy for spinal cord defect: human dental follicle cells combined with aligned PCL/PLGA electrospun material," BioMed Research International, vol. 2015, Article ID 197183, 12 pages, 2015.

[228] A. C. C. Koyuncu, G. G. Pekozer, M. Ramazanoglu, G. T. Kose, and V. Hasirci, "Cartilage tissue engineering on macroporous scaffolds using human tooth germ stem cells," Journal of Tissue Engineering and Regenerative Medicine, vol. 11, no. 3, pp. 765-777, 2017.

[229] M. Yalvac, M. Ramazanoglu, M. Tekguc et al., "Human tooth germ stem cells preserve neuro-protective effects after longterm cryo-preservation," Current Neurovascular Research, vol. 7, no. 1, pp. 49-58, 2010.

[230] P. Van Pham, N. Y. Tran, N. L.-C. Phan, N. B. Vu, and N. K. Phan, "Vitamin C stimulates human gingival stem cell proliferation and expression of pluripotent markers," In Vitro Cellular \& Developmental Biology. Animal, vol. 52, no. 2, pp. 218-227, 2016.

[231] Y. X. Zhong, W. S. Li, L. S. Liao, and L. Liang, "IncRNA CCAT1 promotes cell proliferation and differentiation via negative modulation of miRNA-218 in human DPSCs," European Review for Medical and Pharmacological Sciences, vol. 23, no. 9, pp. 3575-3583, 2019.

[232] L.-D. Zhao, W.-C. Xu, J. Cui et al., "Long non-coding RNA maternally expressed gene 3 inhibits osteogenic differentiation of human dental pulp stem cells via microRNA$543 /$ smad ubiquitin regulatory factor $1 /$ runt-related transcription factor 2 axis," Archives of Oral Biology, vol. 118, p. 104838, 2020.

[233] Y. Xu, C. Ren, X. Zhao, W. Wang, and N. Zhang, "MicroRNA-132 inhibits osteogenic differentiation of periodontal ligament stem cells via GDF5 and the NF- $\kappa$ B signaling path- way," Pathology - Research and Practice, vol. 215, no. 12, p. 152722, 2019.

[234] Y. Liu, C. Liu, A. Zhang et al., "Down-regulation of long noncoding RNA MEG3 suppresses osteogenic differentiation of periodontal ligament stem cells (PDLSCs) through miR27a-3p/IGF1 axis in periodontitis," Aging, vol. 11, no. 15, pp. 5334-5350, 2019.

[235] Z. Li, X. Guo, and S. Wu, "Epigenetic silencing of KLF2 by long non-coding RNA SNHG1 inhibits periodontal ligament stem cell osteogenesis differentiation," Stem Cell Research \& Therapy, vol. 11, no. 1, p. 435, 2020.

[236] L. Wang, F. Wu, Y. Song et al., "Long noncoding RNA related to periodontitis interacts with miR-182 to upregulate osteogenic differentiation in periodontal mesenchymal stem cells of periodontitis patients," Cell Death \& Disease, vol. 7, no. 8 , article e2327, 2016.

[237] L. Wang, F. Wu, Y. Song et al., "Long noncoding RNA TUG1 facilitates osteogenic differentiation of periodontal ligament stem cells via interacting with Lin28A," Cell Death \& Disease, vol. 9 , no. 5, p. 455, 2018.

[238] L. Y. Di Wu, D. Sun, F. Wang, Q. Wu, Q. Xu, and B. Xin, "Long noncoding RNA TUG1 promotes osteogenic differentiation of human periodontal ligament stem cell through sponging microRNA-222-3p to negatively regulate Smad2/7," Archives of Oral Biology, vol. 117, p. 104814, 2020.

[239] Y. Feng, P. Wan, and L. Yin, "Long noncoding RNA Xinactive specific transcript (XIST) promotes osteogenic differentiation of periodontal ligament stem cells by sponging microRNA-214-3p," Medical Science Monitor, vol. 26, 2020.

[240] Y. Wang, Y. Sun, P. Zheng et al., "Long non-coding RNAs mortal obligate RNA transcript regulates the proliferation of human periodontal ligament stem cells and affects the recurrence of periodontitis," Archives of Oral Biology, vol. 105, pp. 1-4, 2019.

[241] H. Yang, J. Fan, Y. Cao, R. Gao, and Z. Fan, "Distal-less homeobox 5 promotes the osteo-/dentinogenic differentiation potential of stem cells from apical papilla by activating histone demethylase KDM4B through a positive feedback mechanism," Experimental Cell Research, vol. 374, no. 1, pp. 221-230, 2019.

[242] J.-J. Wang, R. Dong, L.-P. Wang et al., "Histone demethylase KDM2B inhibits the chondrogenic differentiation potentials of stem cells from apical papilla," International Journal of Clinical and Experimental Medicine, vol. 8, no. 2, pp. 21652173, 2015.

[243] C. Zhang, X. Han, Y. Liang, H. Liu, Z. Fan, and J. Zhang, "The histone demethylase KDM3B promotes osteo-/odontogenic differentiation, cell proliferation, and migration potential of stem cells from the apical papilla," Stem Cells International, vol. 2020, Article ID 8881021, 14 pages, 2020.

[244] F. Sun, M. Wan, X. Xu et al., "Crosstalk between miR-34a and Notch signaling promotes differentiation in apical papilla stem cells (SCAPs)," Journal of Dental Research, vol. 93, no. 6, pp. 589-595, 2014.

[245] Z. Li, X. Ge, J. Lu et al., "MiR-141-3p regulates proliferation and senescence of stem cells from apical papilla by targeting YAP," Experimental Cell Research, vol. 383, no. 2, 2019.

[246] Z. Li, M. Yan, Y. Yu et al., "IncRNA H19 promotes the committed differentiation of stem cells from apical papilla via miR-141/SPAG9 pathway," Cell Death \& Disease, vol. 10, no. 2, p. 130, 2019. 
[247] L. Deng, H. Hong, X. Zhang et al., "Down-regulated lncRNA MEG3 promotes osteogenic differentiation of human dental follicle stem cells by epigenetically regulating Wnt pathway," Biochemical and Biophysical Research Communications, vol. 503, no. 3, pp. 2061-2067, 2018.

[248] Z. Chen, J. Zheng, H. Hong et al., "IncRNA HOTAIRM1 promotes osteogenesis of hDFSCs by epigenetically regulating HOXA2 via DNMT1 in vitro," Journal of Cellular Physiology, vol. 235, no. 11, pp. 8507-8519, 2020.

[249] C. Klingelhöffer, C. Codrin, T. Ettl, T. Reichert, and C. Morsczeck, "miRNA-101 supports the osteogenic differentiation in human dental follicle cells," Archives of Oral Biology, vol. 72, pp. 47-50, 2016.

[250] X. Han, H. Yang, Y. Cao et al., "The miR-3940-5p inhibits cell proliferation of gingival mesenchymal stem cells," Oral Diseases, vol. 25, no. 5, pp. 1363-1373, 2019. 